\title{
Five-level inverter scheme for an induction motor drive with simultaneous elimination of common- mode voltage and DC-link capacitor voltage imbalance
}

\author{
P.N. Tekwani, R.S. Kanchan and K. Gopakumar
}

\begin{abstract}
The simultaneous elimination of common-mode voltage and DC-link capacitor voltage imbalance is achieved in a five-level inverter scheme for an induction motor drive throughout its operating range. A dual five-level inverter-fed open-end-winding induction motor structure is used for the proposed drive. Initially, the operating limitations of achieving this dual task for the fivelevel inverter configuration are investigated for a single DC power supply. Subsequently, a switching strategy for a five-level inverter topology with two DC power supplies is proposed to achieve the dual task over the entire speed range of the drive. The proposed drive offers a simple power-bus structure with more redundant switching combinations for inverter voltage vectors, and requires a lower voltage-blocking capacity of the power devices as compared with the conventional single five-level inverter-fed drive. As only the availability of redundant switching combinations for inverter voltage vectors is exploited, the dual task is achieved without disturbing the fundamental component of the inverter output voltage and the scheme does not need any extra control circuit hardware. Experimental verification of the proposed scheme is done on a $1.5 \mathrm{~kW}$ induction motor drive in the linear as well as overmodulation range.
\end{abstract}

\section{Introduction}

All the multilevel inverter configurations, neutral-point clamped (NPC), cascaded H-bridge, flying capacitor, etc., produce alternating common-mode voltages at the motor terminals resulting in bearing currents and ground leakage currents. In the NPC multilevel inverter configuration with a single DC-link power supply, the inherent imbalance in the DC-link capacitor voltages causes lower-order harmonics at the inverter output, torque pulsation and increased voltage stress on the capacitors and power switching devices. In most of the reported works the problems of common-mode voltage [1-5] and capacitor voltage imbalance [6-11] are separately dealt with. A PWM scheme to eliminate the common-mode voltages in conventional three-level NPC inverter is presented in [1] in which the inverter output voltages are generated using only certain inverter states that generate zero common-mode voltage. A PWM strategy for reduction (and not the complete elimination) of common-mode voltage in NPC and cascaded multilevel inverters is suggested in [2] and [3] respectively.

Multilevel inverter schemes realised using an open-endwinding induction motor are presented in $[4,5]$ for the elimination of common-mode voltage throughout the operating range of the drive. These schemes $[4,5]$ offer more redundant switching states for inverter voltage vectors compared with the single inverter-fed drives of the same voltage levels. A control technique that maintains the mean neutral-point current to a minimum value by suitable addition of DC-offset to each of the PWM modulation waves of a three-level NPC inverter is presented in [6] for DC-link capacitor-voltage balancing. Reference [6] also reports the inherent operating limitations of multilevel inverters for achieving capacitor-voltage balancing in both motoring and regenerating modes. With the presence of a larger number of DC-link capacitors and DC-neutral points, the task of achieving the capacitor-voltage balancing becomes inherently more complicated (especially at higher modulation indices) with increasing levels of multilevel NPC inverter $[6,7]$.

Capacitor-voltage balancing schemes presented in [7-9] for five-level NPC inverter suggest the use of extra hardware in addition to the SVPWM or carrier-based PWM control techniques for capacitor-voltage balancing. This extra hardware may be in the form of buck-boost converters (DC choppers) [7, 8] or a back-to-back connection of multilevel NPC-controlled front-end rectifier with a multilevel NPC inverter [9]. A generalised multilevel inverter topology with self voltage balancing, presented in [10], requires 20 switching devices and six additional capacitors per leg of the five-level inverter. Also, the concept is supported only by the steady-state simulation results.

Recently it has been concluded in [11] that voltage balancing of capacitors in a four-level NPC inverter (with single DC-link power supply) is impossible, even if there is no restriction for the selection of redundant vectors (nonoptimal switching) at higher modulation indices if active current components exist. It has been pointed out in the introduction of [12] that neutral-point balancing and 
common-mode voltage cancellation cannot be achieved concurrently in a multilevel NPC inverter. A control scheme for a three-level VSI topology for an open-end-winding induction motor is described in [13] which achieves this dual task throughout the operating range and without using additional hardware.
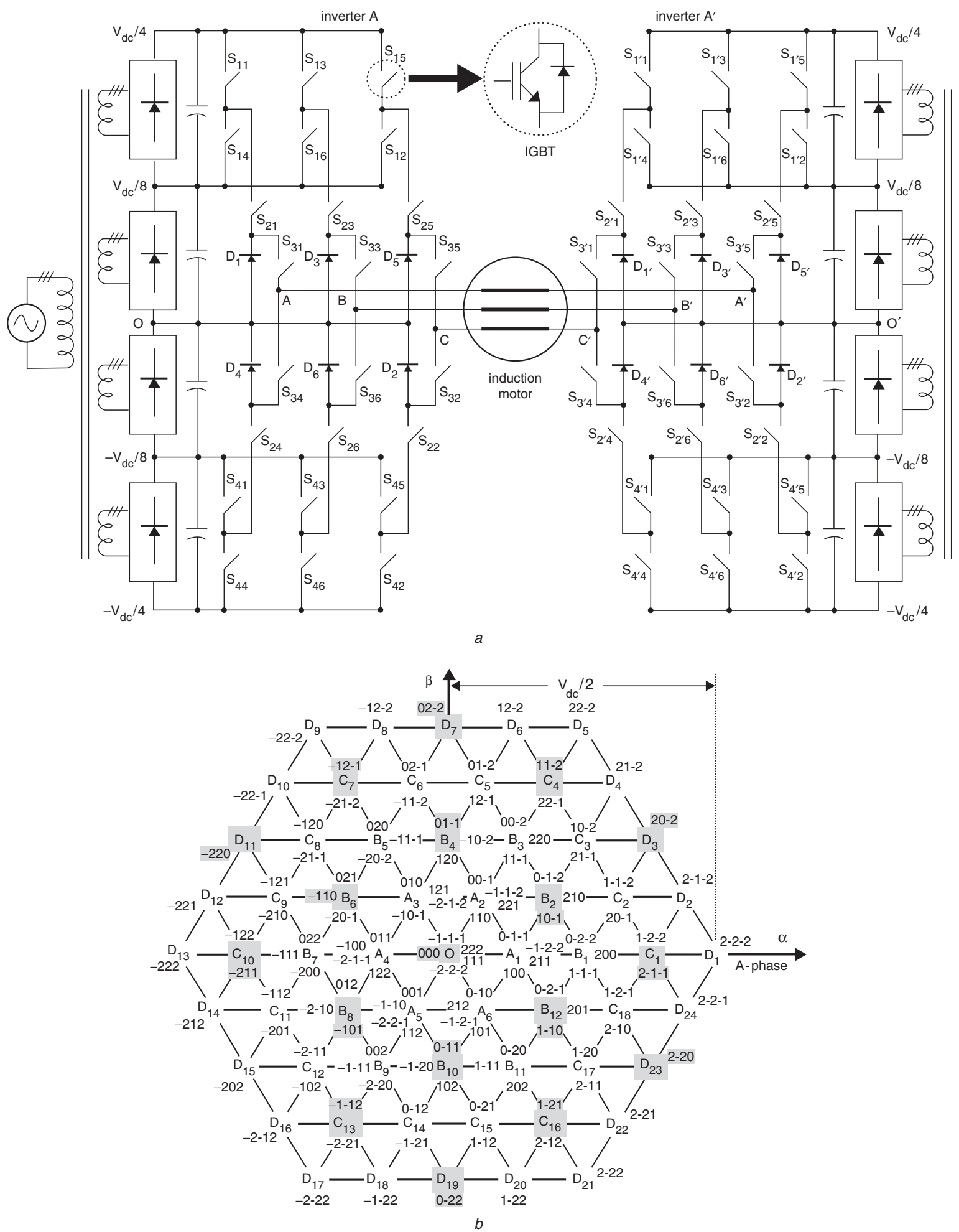

Fig. 1

$a$ Power schematic of dual five-level inverter-fed open-end-winding induction motor

$b$ Switching states and voltage space vector locations of five-level inverter (A or $\mathrm{A}^{\prime}$ ) shown shaded: 19 switching states and corresponding voltage vector locations, generating zero common-mode voltage

$c$ Combined inverter voltage space phasor locations with zero common-mode voltage: 61 voltage space vectors form 96 triangular sectors resulting into five-level inverter voltage space phasor structure

$d$ Number of available redundant switching state combinations for each of combined voltage space vector locations of Fig. 1c (361 switching state combinations possible)

$e$ Power schematic of proposed five-level inverter-fed induction motor drive with single DC power supply to explore possibility of capacitor-voltage balancing with common-mode voltage elimination

$f$ System schematic and five-level DC-bus terminology for proposed inverter fed induction motor drive of Fig. $1 e$ 

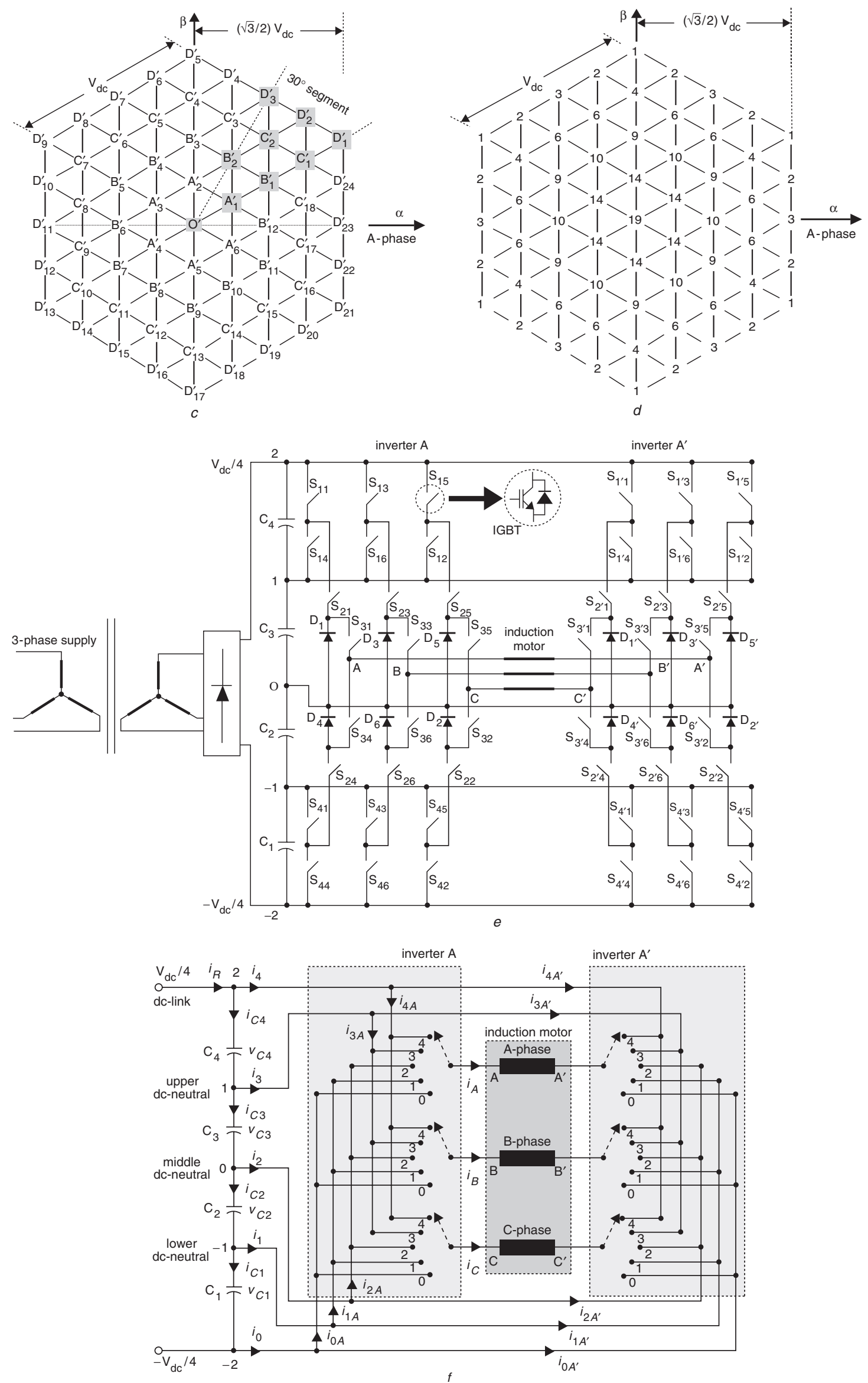

Fig. 1 Continued

A five-level inverter-fed induction motor drive scheme is proposed in the present work for simultaneously achieving the dual task of elimination of common-mode voltage and
DC-link capacitor voltage imbalances. The proposed scheme is based on a dual five-level inverter-fed open-endwinding induction motor configuration [5]. This paper 
Table 1: Generation of five different voltage levels based on state of switches for pole-A of inverter $A^{*}$

\begin{tabular}{|c|c|c|c|c|c|}
\hline \multirow{2}{*}{$\begin{array}{l}\text { Pole voltage } \\
V_{A O}\end{array}$} & \multirow{2}{*}{$\begin{array}{l}\text { Voltage } \\
\text { level }\end{array}$} & \multicolumn{2}{|c|}{ State of switch } & \multirow[b]{2}{*}{$\mathrm{S}_{24}$} & \multirow[b]{2}{*}{$S_{41}$} \\
\hline & & $\mathrm{S}_{11}$ & $\mathrm{~S}_{21}$ & & \\
\hline$V_{d d} 4$ & 2 & 1 & 1 & 0 & 1 \\
\hline$V_{d d} 8$ & 1 & 0 & 1 & 0 & 1 \\
\hline 0 & 0 & 0 & 0 & 0 & 1 \\
\hline$-V_{d d} / 8$ & -1 & 0 & 0 & 1 & 1 \\
\hline$-V_{d d} d 4$ & -2 & 0 & 0 & 1 & 0 \\
\hline
\end{tabular}

${ }^{*} S_{11}$ and $S_{14}, S_{21}$ and $S_{34}, S_{24}$ and $S_{31}$, and $S_{41}$ and $S_{44}$ are four different complementary pairs of switches

** [1 indicates on-state and 0 indicates off-state of the switch] investigates the operating limitations of achieving this dual task for the five-level inverter-fed drive with a single DC power supply. A five-level inverter-fed drive topology with two DC power supplies, and a strategy for selecting the switching states, are proposed to achieve the dual task simultaneously. The proposed inverter-fed drive offers a simple power bus structure with more redundant switching states for inverter voltage vectors, and demands a lower voltage blocking capacity of the power devices, as compared with a single five-level inverter-fed drive. As only the availability of redundant switching states for the inverter voltage vectors is exploited, the dual task is achieved without disturbing the fundamental component of the inverter output voltage and the scheme does not require any extra control circuit hardware.

Table 2: Common-mode voltage generated by switching states of individual five-level inverter ( $A$ and $A^{\prime}$ ) and different groups of switching states which generate same magnitude of common-mode voltage at inverter poles*

\begin{tabular}{|c|c|c|}
\hline Group & Switching state of five-level inverter & $\begin{array}{l}\text { Common-mode voltage } \\
V_{C M A} \text { and } V_{C M A^{\prime}}\end{array}$ \\
\hline 1 & 222 & $V_{d d} / 4$ \\
\hline 2 & $122,212,221$ & $5 V_{d d} 24$ \\
\hline 3 & $022,112,121,202,211,220$ & $V_{d d} 6$ \\
\hline 4 & $012,021,102,111,120,201,210,22-1,2-12,-122$ & $V_{d d} / 8$ \\
\hline 6 & $\begin{array}{l}001,010,02-1,0-12,100,11-1,12-2,1-11,1-22,20-1,21-2,2-10,2-21,-102,-111 \\
-120,-212,-221\end{array}$ & $V_{d d} / 24$ \\
\hline 7 & $\begin{array}{l}000,01-1,02-2,0-11,0-22,10-1,11-2,1-10,1-21,20-2,2-1-1,2-20,-101,-110, \\
-12-1,-1-12,-202,-211,-220\end{array}$ & 0 \\
\hline 8 & $\begin{array}{l}00-1,01-2,0-10,0-21,10-2,1-1-1,1-20,2-1-2,2-2-1,-100,-11-1,-12-2, \\
-1-11,-1-22,-210,-210,-22-1,-2-12\end{array}$ & $-V_{d d} 24$ \\
\hline 10 & $0-1-2,0-2-1,1-2-2,-10-2,-1-1-1,-1-20,-20-1,-21-2,-2-10,-2-21$ & $-V_{d d} / 8$ \\
\hline 11 & $0-2-2,-1-1-2,-1-2-1,-20-2,-2-1-1,-2-20$ & $-V_{d d} 6$ \\
\hline 12 & $-1-2-2,-2-1-2,-2-2-1$ & $-5 V_{d d} / 24$ \\
\hline 13 & $-2-2-2$ & $-V_{d d} 4$ \\
\hline
\end{tabular}

${ }^{*}$ Shaded portion indicates particular group and its switching states which generate zero common-mode voltage at inverter poles

Table 3: Redundant switching-state combinations which provide zero common-mode voltage for different voltage space vectors in $30^{\circ}$ segment of voltage space phasor structure (Fig. 1c) of proposed five-level inverter

\begin{tabular}{ll}
$\begin{array}{l}\text { Voltage space vector location and } \\
\text { available number of redundant } \\
\text { switching-state combinations }\end{array}$ & Redundant switching-state combinations (inverter $A$ switching state, inverter $A^{\prime}$ switching state) \\
\hline $\mathrm{O}^{\prime}(19)$ & $(000,000),(0-11,0-11),(-211,-211),(01-1,01-1),(02-2,02-2),(-220,-220),(0-22,0-22)$, \\
& $(10-1,10-1),(11-2,11-2),(1-10,1-10),(1-21,1-21),(20-2,20-2),(2-1-1,2-1-1),(2-20,2-20)$, \\
& $(-101,-101),(-110,-110),(-12-1,-12-1),(-1-12,-1-12),(-202,-202)$ \\
$A_{1}^{\prime}(14)$ & $(10-1,000),(000,-101),(20-2,10-1),(01-1,-110),(-101,-202),(02-2,-12-1),(0-11,-1-12)$, \\
& $(-12-1,-220),(11-2,01-1),(1-10,0-11),(1-21,0-22),(2-1-1,1-10),(-110,-211),(2-20,1-21)$ \\
$B_{1}^{\prime}(9)$ & $(000,-202),(10-1,-101),(01-1,-211),(1-10,-1-12),(02-2,-220),(2-1-1,0-11),(11-2,-110)$, \\
& $(20-2,000),(2-20,0-22)$ \\
$B_{2}^{\prime}(10)$ & $(000,-1-12),(10-1,0-11),(01-1,-101),(1-10,0-22),(02-2,-110),(2-1-1,1-21),(11-2,000)$, \\
& $(-12-1,-211),(20-2,1-10),(-110,-202)$ \\
$C_{1}^{\prime}(4)$ & $(10-1,-202),(11-2,-211),(20-2,-101),(2-1-1,-1-12)$ \\
$C_{2}^{\prime}(6)$ & $(01-1,-202),(02-2,-211),(10-1,-1-12),(11-2,-101),(20-2,0-11),(2-1-1,0-22)$ \\
$D_{1}^{\prime}(1)$ & $(20-2,-202)$ \\
$D_{2}^{\prime}(2)$ & $(11-2,-202),(20-2,-1-12)$ \\
$D_{3}^{\prime}(3)$ & $(02-2,-202),(11-2,-1-12),(20-2,0-22)$ \\
&
\end{tabular}




\section{Realisation of five-level inverter fed IM drive with common-mode voltage elimination}

Figure $1 a$ shows the schematic of the proposed dual inverter-fed open-end-winding induction motor drive, where inverter $\mathrm{A}$ and inverter $\mathrm{A}^{\prime}$ are five-level inverters. As the proposed five-level inverter is formed by cascading conventional two-level inverters and a three-level NPC inverter, it offers a simple power-bus structure compared with that of a five-level NPC inverter. The drive (Fig. 1a) requires a total DC-link voltage of $V_{d c} / 2$, where $V_{d c}$ is the required DC-link voltage for a single five-level inverter-fed drive. Table 1 shows the states of the switches to generate five different voltage levels at pole A of inverter A (Fig. 1a). The requirement of blocking voltage capability of individual devices is as low as $V_{d c} / 8$ for $\mathrm{S}_{11}, \mathrm{~S}_{14}, \mathrm{~S}_{41}$ and $\mathrm{S}_{44}$, while it is $V_{d c} / 5.33$ (i.e. $\left.3 \times V_{d c}\right) /(2 \times 8)$ for $\mathrm{S}_{21}, \mathrm{~S}_{34}, \mathrm{~S}_{24}$ and $\mathrm{S}_{31}$ in the drive topology of Fig. 1a. If $V_{A O}, V_{B O}$ and $V_{C O}$ are the pole voltages of inverter $\mathrm{A}$, and $V_{A^{\prime} O^{\prime}}, V_{B^{\prime} O^{\prime}}$ and $V_{C^{\prime} O^{\prime}}$ are the pole voltages of inverter $\mathrm{A}^{\prime}$ (Fig. 1a), then the voltage space vector for inverters $\mathrm{A}$ and $\mathrm{A}^{\prime}$ can be represented as (1). All the possible switching states and resultant voltage space vectors of the five-level inverter (A or $\left.\mathrm{A}^{\prime}\right)$ are shown in Fig. $1 b$ [5]. For example, considering Fig. $1 b$ for inverter A, a switching level (hereafter termed the switching state) ' -102 ' (space vector $\mathrm{C}_{12}$ ) means pole voltage $V_{A O}, V_{B O}$ and $V_{C O}$ are equal to $-V_{d c} / 8,0$, and $V_{d c} / 4 \mathrm{~V}$, respectively (Table 1). The resultant voltage across the motor phase windings when both the five-level inverters ( $\mathrm{A}$ and $\mathrm{A}^{\prime}$, Fig. 1a) are switching independently can be given as (2) and the combined voltage space vector for proposed inverter (Fig. 1a) is expressed as (3). The common-mode voltage generated by inverters $\mathrm{A}_{\text {and }} \mathrm{A}^{\prime}$ (Fig. 1a) is expressed as (4) $[4,5]$. Hence the resultant common-mode voltage appearing at the motor phase windings can be represented as (5).

$$
\begin{gathered}
V_{S R 1}=V_{A O}+V_{B O} e^{j 120^{\circ}}+V_{C O} e^{j 240^{\circ}}, \quad \text { and } \\
V_{S R 2}=V_{A^{\prime} O^{\prime}}+V_{B^{\prime} O^{\prime}} e^{j 120^{\circ}}+V_{C^{\prime} O^{\prime}} e^{j 240^{\circ}} \\
V_{A A^{\prime}}=V_{A O}-V_{A^{\prime} O^{\prime}}, \quad V_{B B^{\prime}}=V_{B O}-V_{B^{\prime} O^{\prime}}, \\
\text { and } \quad V_{C C^{\prime}}=V_{C O}-V_{C^{\prime} O^{\prime}} \\
V_{S R}=V_{A A^{\prime}}+V_{B B^{\prime}} e^{j 120^{\circ}}+V_{C C^{\prime}} e^{j 240^{\circ}} \\
V_{C M A}=\left(V_{A O}+V_{B O}+V_{C O}\right) / 3, \quad \text { and } \\
V_{C M A^{\prime}}=\left(V_{A^{\prime} O^{\prime}}+V_{B^{\prime} O^{\prime}}+V_{C^{\prime} O^{\prime}}\right) / 3 \\
V_{C M}=V_{C M A}-V_{C M A^{\prime}}
\end{gathered}
$$

The DC-links for inverters $\mathrm{A}$ and $\mathrm{A}^{\prime}$ of Fig. $1 a$ are isolated to prevent the flow of zero sequence currents in the machine phase windings $[4,5]$. The magnitude of common-mode voltages generated by inverters $\mathrm{A}$ and $\mathrm{A}^{\prime}$ for all the possible 125 switching states (Fig. 1b) is analysed in the proposed work (Table 2). The switching states, which generate zero common-mode voltage at the inverter poles (a total of 19 switching states of group 7 of Table 2, shown shaded in Fig. 1b), are only used to switch the individual five-level inverters (A and $\mathrm{A}^{\prime}$ ) of Fig. 1 $a$. This results in a five-level inverter voltage space vector structure (with a $15 \%$ boost in DC-link voltage to get the maximum peak value of the phase voltage the same as that of single five-level NPC inverter-fed drive [14]) as shown in Fig. 1c, which generates zero common-mode voltage. Consequently four isolated DC power supplies (out of a total of eight) can be removed from the power schematic shown in Fig. 1a, and inverters $\mathrm{A}$ and $\mathrm{A}^{\prime}$ are supplied with common $\mathrm{DC}$-links (requiring only four isolated DC power supplies). The available number of redundant switching-state combinations for each of the voltage space vector locations of Fig. $1 c$ is shown in Fig. $1 d$; a total of $361(19 \times 19)$ switching-state combinations are available. Hence, the proposed drive configuration offers an increased number of redundant switching-state combinations for inverter voltage vectors as compared with a single five-level inverter-fed drive. This makes the proposed drive more suitable for simultaneously achieving the dual task of common-mode voltage elimination and DC-link capacitorvoltage balancing.

Figure $1 c$ exhibits a $30^{\circ}$ symmetry, and hence a $30^{\circ}$ segment $\left(\mathrm{D}^{\prime}{ }_{1} \mathrm{O}^{\prime} \mathrm{D}^{\prime}{ }_{3}\right)$ of Fig. $1 c$ is considered for further analysis in this paper. The switching-state combinations (which generate zero common-mode voltage) for different space vectors in the $30^{\circ}$ segment $\left(\mathrm{D}^{\prime}{ }_{1} \mathrm{O}^{\prime} \mathrm{D}^{\prime}{ }_{3}\right)$ are shown in Table 3. A number in the bracket adjacent to each space vector in the first column of Table 3 indicates the total redundant switching states (Fig. 1d) available for generating that particular voltage vector. For example, if inverter A is switched with state '-101' and inverter $\mathrm{A}^{\prime}$ ' is switched with state ' -202 ', then the switching state combination becomes ' $-101,-202$ ' (Table 3), which results into a combined voltage space vector $\mathrm{A}_{1}^{\prime}$ (Table 3, Fig. 1c).

\section{Analysis of DC-link capacitor voltage variations}

Instead of using four isolated DC power supplies (Section 2), a preferred practical approach is to provide a single DC-link of voltage $V_{d c} / 2$ (for ease of analysis, neglecting the required DC-link boost [4, 5], Section 2) and to split it into four equal voltage levels of $V_{d c} / 8$ using a bank of four capacitors. This arrangement of power schematic for the proposed scheme is shown in Fig. 1e. The schematic of the proposed inverter fed induction motor drive is shown in Fig. $1 f$ with the five-level DC-bus terminology, where each leg of the inverter is represented as a switch. The five different voltage levels of pole voltage (Table 1) are represented as 2, 1, 0, -1 and -2 in Fig. $1 f$. The motor currents are denoted as $i_{A}, i_{B}$ and $i_{C}$. Total current drawn by the dual inverter from the negative DC-bus, lower

Table 4: Grouping of inverter voltage space vectors of Fig. $1 c$

\begin{tabular}{ll}
\hline $\begin{array}{l}\text { Voltage space } \\
\text { vector locations }\end{array}$ & Group \\
\hline $\mathrm{O}^{\prime}$ & Zero voltage vector $\mathrm{ZV}$ \\
$\mathrm{A}_{1}^{\prime}$ to $\mathrm{A}_{6}^{\prime}$ & Two-level voltage vectors $2 \mathrm{LV}$ \\
$\mathrm{B}_{1}^{\prime}$ to $\mathrm{B}_{12}^{\prime}$ & Three-level voltage vectors $3 \mathrm{LV}$ \\
$\mathrm{C}_{1}^{\prime}$ to $\mathrm{C}_{18}^{\prime}$ & Four-level voltage vectors $4 \mathrm{LV}$ \\
$\mathrm{D}_{1}^{\prime}$ to $\mathrm{D}_{24}^{\prime}$ & Five-level voltage vectors $5 \mathrm{LV}$ \\
\hline
\end{tabular}

Table 5: Assignment of signs to machine phase currents for node current analysis

\begin{tabular}{ll}
\hline Current direction* ${ }^{*}(X=A, B, C)$, Fig. $\left.1 f\right]$ & $\begin{array}{l}\text { Assignment of } \\
\text { sign to current }\end{array}$ \\
\hline Current entering to DC-link node from $X^{\prime}$ & Negative \\
Current entering to DC-link node from $X$ & Positive \\
Current leaving from DC-link node to $X^{\prime}$ & Negative \\
Current leaving from DC-link node to $X$ & Positive \\
\hline
\end{tabular}




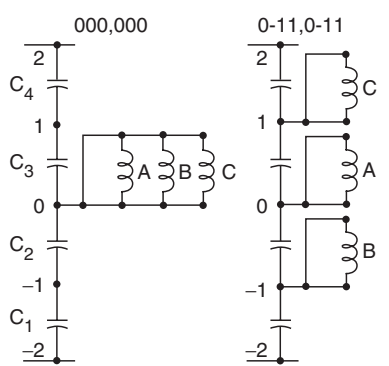

a

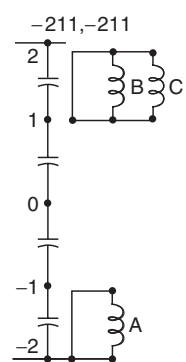

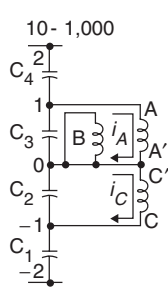
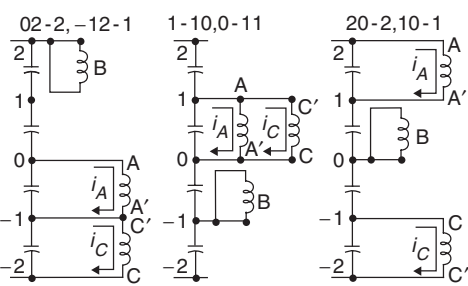

$b$
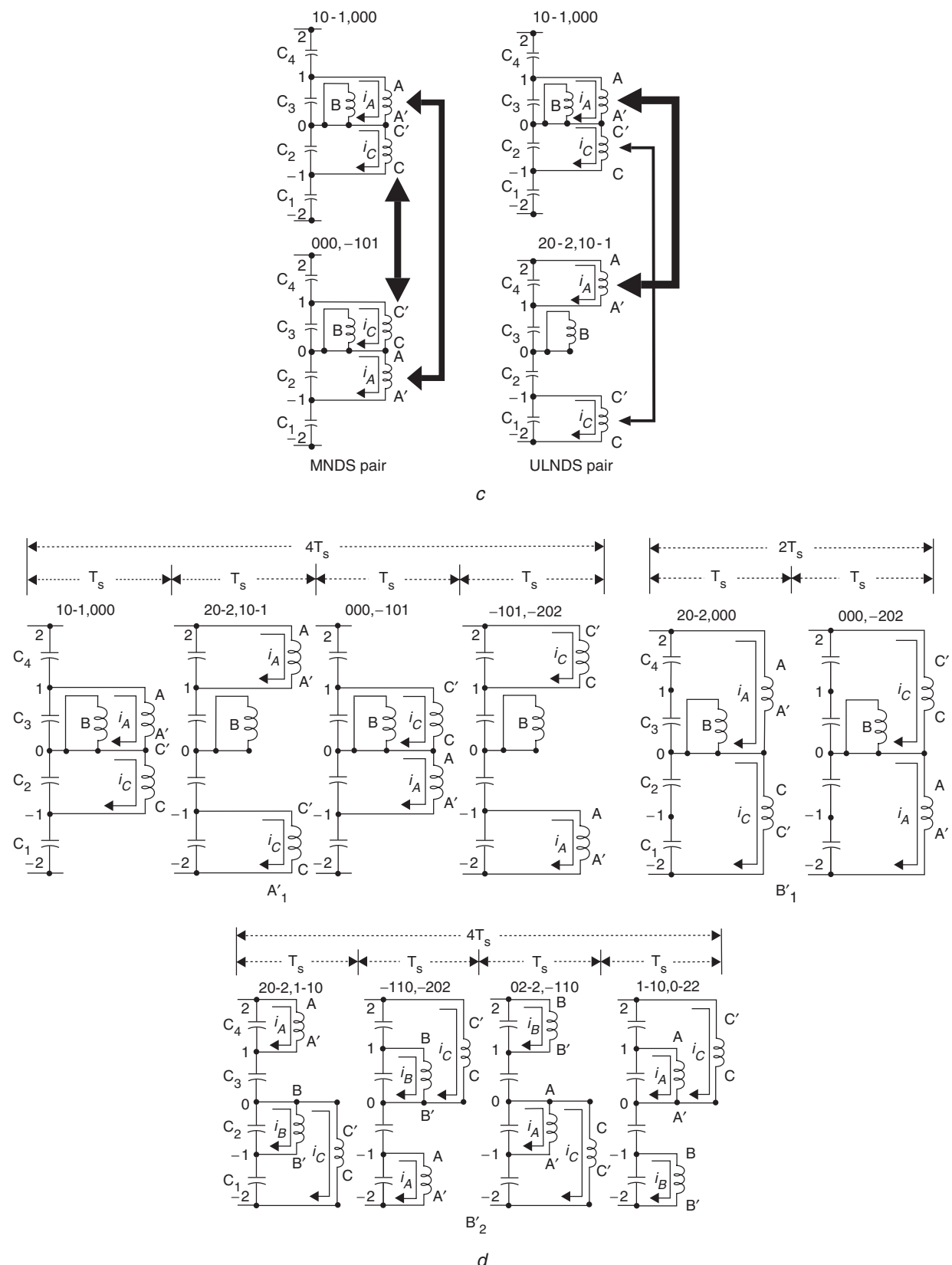

Fig. 2

$a$ Connection of machine phase windings with DC-link nodes for few of redundant switching-state combinations for voltage space vector $\mathrm{O}^{\prime}$ of $\mathrm{ZV}$ group

$b$ Connection of machine phase windings with DC-link nodes for few of redundant switching-state combinations for voltage space vector $\mathrm{A}^{\prime}{ }_{1}$ of $2 \mathrm{LV}$ group

$c$ One of MNDS and ULNDS pairs of voltage space vector $\mathrm{A}^{\prime}{ }_{1}$ of $2 \mathrm{LV}$ group

$d$ Selection of MNDS or ULNDS pairs for different voltage vectors in different sampling intervals for position of reference voltage space vector in sector formed by inverter voltage space vectors $\mathrm{A}_{1}{ }_{1}, \mathrm{~B}^{\prime}{ }_{1}$ and $\mathrm{B}_{1}{ }_{1}$ (three-level operation)

$e$ Sequence of proposed switching-state combinations for capacitor-voltage balancing when reference voltage space vector is in sector formed by inverter voltage space vectors $\mathrm{A}^{\prime}{ }_{1}, \mathrm{~B}^{\prime}{ }_{1}$ and $\mathrm{B}_{2}{ }_{2}$ (three-level operation)

$f$ Sequence of switching-state combinations to examine possibility of capacitor-voltage balancing within two consecutive sampling intervals when reference voltage space vector is in sector formed by inverter voltage space vectors $\mathrm{B}_{1}^{\prime}, \mathrm{B}_{2}^{\prime}$ and $\mathrm{C}_{2}^{\prime}$ (four-level operation) 


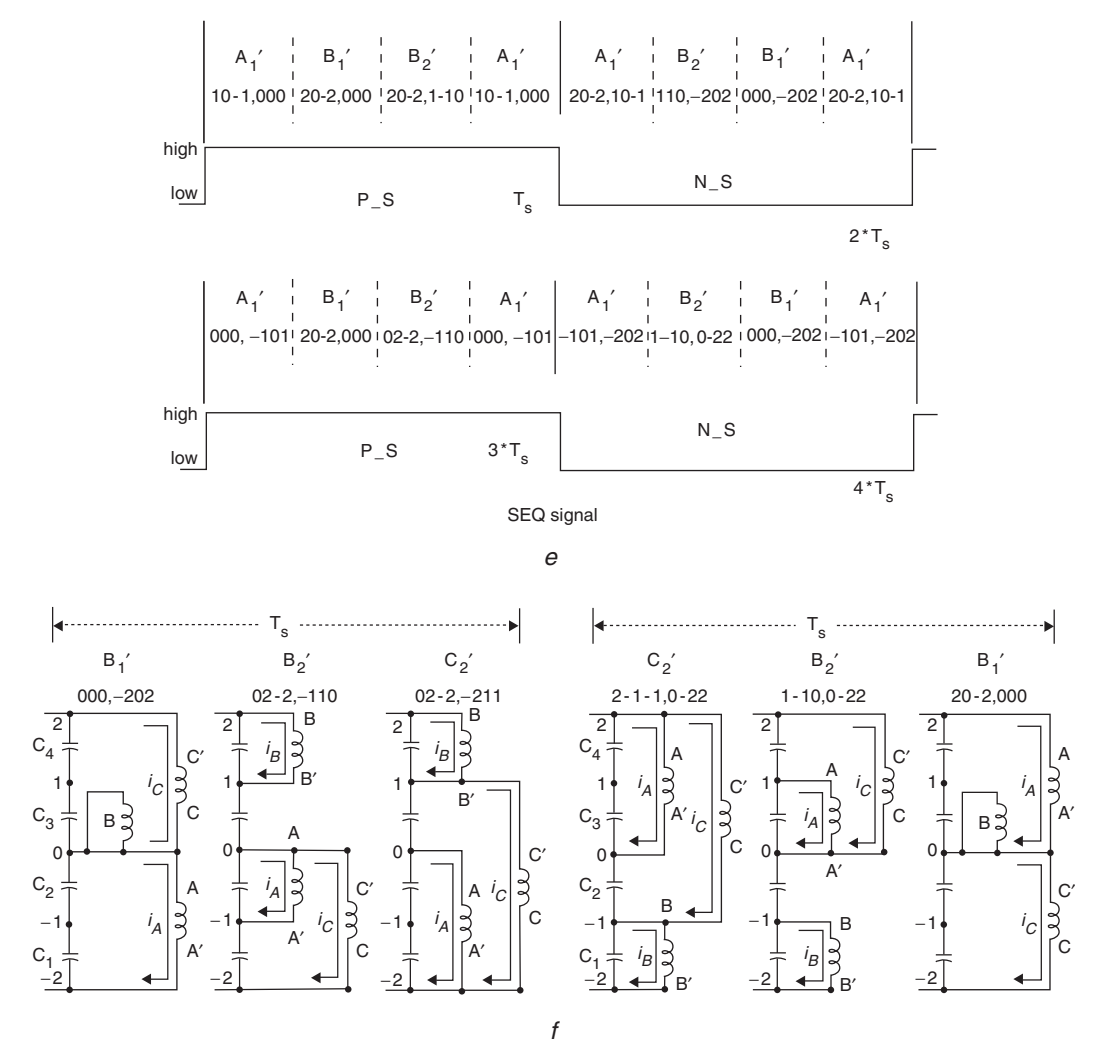

Fig. 2 Continued

DC-neutral, middle DC-neutral, upper DC-neutral, and positive DC-bus are referred as $i_{0}, i_{1}, i_{2}, i_{3}$ and $i_{4}$, respectively. In a similar way, inverter $\mathrm{A}$ input currents are referred as $i_{0 A}, i_{1 A}, i_{2 A}, i_{3 A}$ and $i_{4 A}$, while inverter $\mathrm{A}^{\prime}$ input currents are referred as $i_{0 A^{\prime}}, i_{1 A}^{\prime}, i_{2 A^{\prime}}, i_{3 A^{\prime}}$ and $i_{4 A^{\prime}}$. Rectifier current is represented by $i_{R}$. Voltages across the capacitors $C_{1}, C_{2}, C_{3}$ and $C_{4}$ are denoted as $v_{C 1}, v_{C 2}, v_{C 3}$ and $v_{C 4}$.

From Fig. $1 f$, for a balanced three-phase load (i.e. $i_{A}+i_{B}+i_{C}=0$ and $i_{0}+i_{1}+i_{2}+i_{3}+i_{4}=0$ ), the currents flowing through the capacitors can be represented as in (6) and (7). For $C_{1}=C_{2}=C_{3}=C_{4}=C$, and from (7), the relationship of capacitor voltages with DC-link node currents and rectifier current can be given as in (8). Using (8), the difference between voltages of adjacent capacitors of inverter-fed induction motor drive (Fig. 1f) can be given as in (9).

$$
\begin{aligned}
& i_{C 4}=i_{R}-i_{4}=i_{R}+\left(i_{0}+i_{1}+i_{2}+i_{3}\right), \quad i_{C 3}=i_{C 4}-i_{3}, \\
& i_{C 2}=i_{C 3}-i_{2}, \quad \text { and } \quad i_{C 1}=i_{C 2}-i_{1} \\
& \therefore\left[\begin{array}{l}
i_{C 4} \\
i_{C 3} \\
i_{C 2} \\
i_{C 1}
\end{array}\right]=\left[\begin{array}{lllll}
1 & 1 & 1 & 1 & 1 \\
1 & 0 & 1 & 1 & 1 \\
1 & 0 & 0 & 1 & 1 \\
1 & 0 & 0 & 0 & 1
\end{array}\right]\left[\begin{array}{l}
i_{R} \\
i_{3} \\
i_{2} \\
i_{1} \\
i_{0}
\end{array}\right] \\
& {\left[\begin{array}{l}
v_{C 4} \\
v_{C 3} \\
v_{C 2} \\
v_{C 1}
\end{array}\right]=\frac{1}{C} \int\left\{\left[\begin{array}{llll}
1 & 0 & 0 & 0 \\
0 & 1 & 0 & 0 \\
0 & 0 & 1 & 0 \\
0 & 0 & 0 & 1
\end{array}\right]\left[\begin{array}{c}
i_{C 4} \\
i_{C 3} \\
i_{C 2} \\
i_{C 1}
\end{array}\right] d t\right\}} \\
& =\frac{1}{C} \int\left\{\left[\begin{array}{lllll}
1 & 1 & 1 & 1 & 1 \\
1 & 0 & 1 & 1 & 1 \\
1 & 0 & 0 & 1 & 1 \\
1 & 0 & 0 & 0 & 1
\end{array}\right]\left[\begin{array}{c}
i_{R} \\
i_{3} \\
i_{2} \\
i_{1} \\
i_{0}
\end{array}\right] d t\right\}
\end{aligned}
$$

$$
\begin{aligned}
\Delta v_{C U} & =v_{C 4}-v_{C 3}=\frac{1}{C} \int i_{3} d t, \quad \Delta v_{C M}=v_{C 3}-v_{C 2} \\
& =\frac{1}{C} \int i_{2} d t, \quad \text { and } \Delta v_{C L}=v_{C 2}-v_{C 1}=\frac{1}{C} \int i_{1} d t
\end{aligned}
$$

It is evident from (9) that the net current drawn from the DC-link nodes ' 1 ', ' 0 ' and ' -1 ' are responsible for capacitor voltage imbalances. Thus the balanced DC-link condition (i.e. $\Delta v_{C U}=\Delta v_{C M}=\Delta v_{C L}=0$ ) occurs when net currents drawn from upper, middle and lower DC-neutrals are zero (i.e. $i_{3}=i_{2}=i_{1}=0$, Fig. $1 f$ ).

\section{Effects of different switching-state combina- tions on variation of capacitor voltages}

For ease of analysis all the inverter voltage vectors of Fig. $1 c$ are divided into five main groups as shown in Table 4. The effects of redundant switching-state combinations of voltage space vectors (Table 3 ) belonging to each of these groups on the charging and discharging of the DC-link capacitors are studied. Based on the connection of machine phase winding terminals with the DC-link nodes, the currents drawn from the DC-link nodes to the machine phase windings and vice versa are assigned with proper signs, as given in Table 5.

It is found for all the switching-state combinations of voltage vector $\mathrm{O}^{\prime}$ ( $\mathrm{ZV}$ group, Table 4) that there is no flow of currents to or from any of the DC-link nodes as the motor phases are not connected across any of the capacitors. Hence, switching-state combinations of the ZV group do not have any effect on capacitor voltages. A few examples of this are given in Fig. $2 a$. For the capacitorvoltage balancing point of view, all the switching-state combinations of the ZV group are equivalently represented as ' $z, z, z$ ', in terms of the currents flowing through DC-link nodes ' 1 ', ' 0 ' and ' -1 ' (i.e. $i_{3}, i_{2}$ and $i_{1}$, Fig. $1 f$ ), respectively. 
Table 6: Equivalent representation of all redundant switching-state combinations for different voltage space vectors and available MDNS and ULDNS pairs of switching-state combinations in $30^{\circ}$ segment of voltage space phasor structure*

Voltage vector and All available redundant switching-state combinations with respective equivalent representation and possible MNDS and ULNDS available number

of switching states combinations

Pair of middle DC-neutral dual switching-state Pair of upper and lower DC-neutral dua combinations (MNDS)

$\mathrm{O}^{\prime}(19)(\mathrm{VV})$

$\mathrm{A}^{\prime}{ }_{1}(14)(2 \mathrm{LV})$

$\mathrm{C}^{\prime}{ }_{1}(4)(4 \mathrm{LV})$

$\mathrm{C}_{2}^{\prime}$ (6) (4LV)

$\mathrm{D}^{\prime}{ }_{1}(1)(5 \mathrm{LV})$

$01-1,-202$
$i_{B r}\left(i_{A}-i_{B}\right), i_{C}$
$02-2,-211$
$\left(-i_{B}-i_{C}\right), i_{A}, z$
$10-1,-1-12$
$i_{A}, i_{B},\left(-i_{A}-i_{B}+i_{C}\right)$

20-2,0-11

$-i_{C}\left(-i_{A}+i_{B}\right),-i_{B}$

2-1-1, 0-22

$z,-i_{A},\left(i_{B}+i_{C}\right)$

$11-2,-101$

$\left(i_{A}+i_{B}-i_{C}\right),-i_{B},-i_{A}$ switching-state combinations (ULNDS)
$02-2,-12-1$

$z, i_{A},\left(-i_{A}-i_{C}\right)$

1-21, 0-22

$\left(i_{A}+i_{C}\right),-i_{A}, z$

11-2, 01-1

$i_{A,}-i_{A},-i_{C}$

$-110,-211$

$-i_{C}, i_{C}, i_{A}$

000. -101

$-i_{C}\left(i_{A}+i_{C}\right),-i_{A}$

10-1, 000

$i_{A},\left(-i_{A}-i_{C}\right), i_{C}$
Other switching-state any MNDS or ULNDS pair

All equivalently represented as; $z, z, z$ combinations which do not form
10-1, - 101

$\left(i_{A}-i_{C}\right), z_{,}\left(-i_{A}+i_{C}\right)$

$-12-1,-220$
$z,-i_{C_{r}}\left(i_{A}+i_{C}\right)$
$2-20,1-21$
$\left(-i_{A}-i_{C}\right), i_{C r} z$
$2-1-1,1-10$
$-i_{A},-i_{C}, i_{C}$
$0-11,-1-12$
$i_{C r} i_{A},-i_{A}$
$-101,-202$
$i_{C r} z, i_{A}$
$20-2,10-1$
$-i_{A}, z_{r}-i_{C}$

$z, i_{A}$

$02-2,-220$

$i_{A},-i_{C},-i_{A}$

$-i_{C}-i_{A}$

11-2, 000

$02-2,-110$

$-110,-202$

2-1-1, 1-21

$i_{B}\left(-i_{B}+i_{C}\right), i_{A}$

$\left(-i_{A}-i_{C}\right), z,\left(i_{B}+i_{C}\right.$

20-2, 1-10

$-i_{A},\left(i_{B}-i_{C}\right),-i_{B}$

1-10, 0-22

$-12-1,-211$

$i_{A},\left(-i_{A}+i_{C}\right), i_{B}$

$\left(-i_{B}-i_{C}\right), z,\left(i_{A}+i_{C}\right)$

$\begin{array}{ll}10-1,-202 & 11-2,-211 \\ i_{A}, z, i_{C} & \left(i_{A}-i_{C}\right), z, z \\ 20-2,-101 & 2-1-1,-1-12 \\ -i_{C}, z,-i_{A} & z, z,\left(-i_{A}+i_{C}\right)\end{array}$

$20-2,-202$

$z, z, z$

$11-2,-1-12$

$\left(i_{A}+i_{B}\right), z,\left(-i_{A}+i_{B}\right)$

$\begin{array}{lll}\mathrm{D}^{\prime}{ }_{2}(2)(5 \mathrm{LV}) & 11-2,-202 & 20-2,-1-12 \\ & \left(i_{A}+i_{B}\right),-i_{B}, z & z, i_{B},\left(-i_{A}-i_{B}\right) \\ \mathrm{D}^{\prime}{ }_{3} \text { (3) (5LV) } & 02-2,-202 & 20-2,0-22 \\ & z_{,}\left(i_{A}-i_{B}\right), z & z,\left(-i_{A}+i_{B}\right), z\end{array}$

${ }^{*}$ Each switching state combination, that forms ULNDS pair with some switching-state combination, and which also form MNDS pair with some other switching-state combination of same voltage vector is marked shaded

Here ' $z$ ' indicates zero current. Similarly, based on Table 5 and as shown in Fig. $2 b$, the switching-state combination ' $10-1,000$ ' (voltage vector $A^{\prime}$ of $2 \mathrm{LV}$ group, Table 3 ) can be equivalently represented as ' $i_{A},\left(-i_{A}-i_{C}\right), i_{C}$ ', in terms of the DC-link node currents $i_{3}, i_{2}$ and $i_{1}$. Based on this equivalent representation and (9) it is found that ' $10-1,000$ ' 

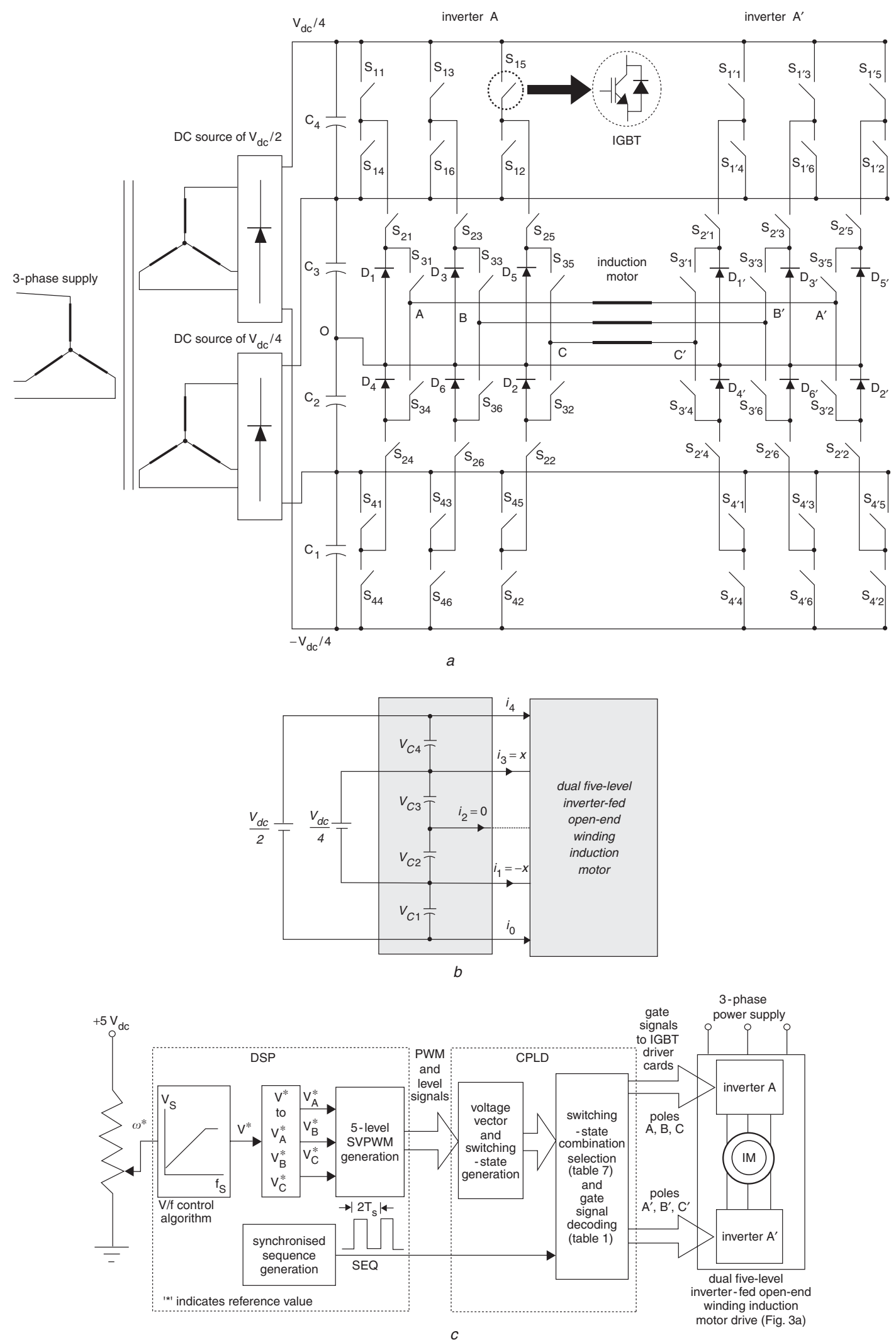

Fig. 3

$a$ Power schematic of proposed five-level inverter with capacitor-voltage balancing and common-mode voltage elimination $b 2 T_{s}$ equivalent block schematic of proposed inverter topology of Fig. $3 a$ during four-level or five-level operation $c$ Block diagram of $V / f$ control scheme used for proposed drive

$d$ Transition from three-level to four-level and four-level to five-level mode of operation: machine phase voltage $V_{A A^{\prime}}$

$e$ Common-mode $V_{C M}$ for operation of Fig. $3 d$

$f$ Voltages of DC-link capacitors for operation of Fig. $3 d$

$g$ Transition from five-level to over-modulation operation: machine phase voltage $V_{A A^{\prime}}$

$h$ Common-mode voltage $V_{C M}$ for operation of Fig. $3 g$

$i$ Voltages of DC-link capacitors for operation of Fig. $3 g$ 

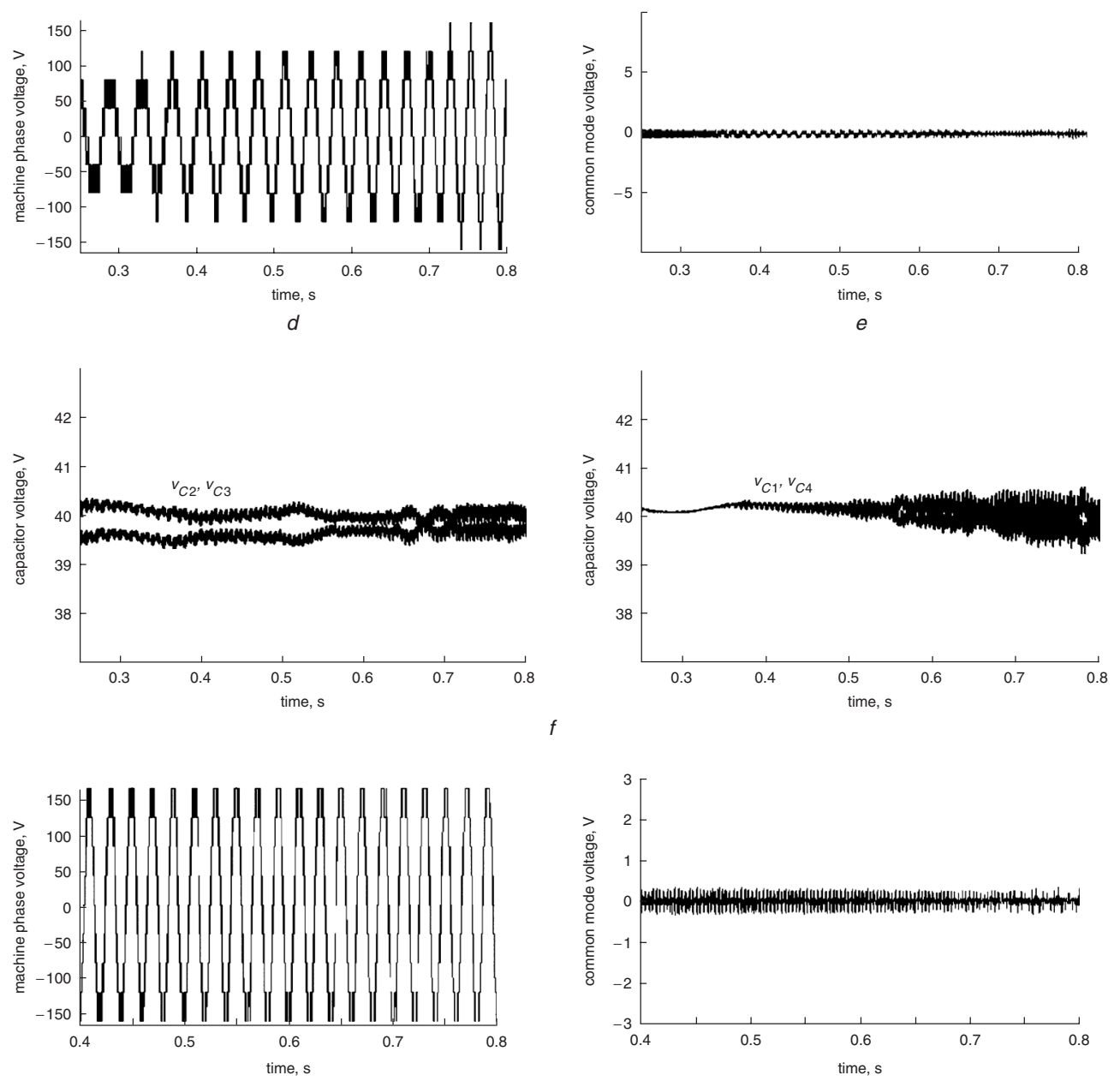

$g$
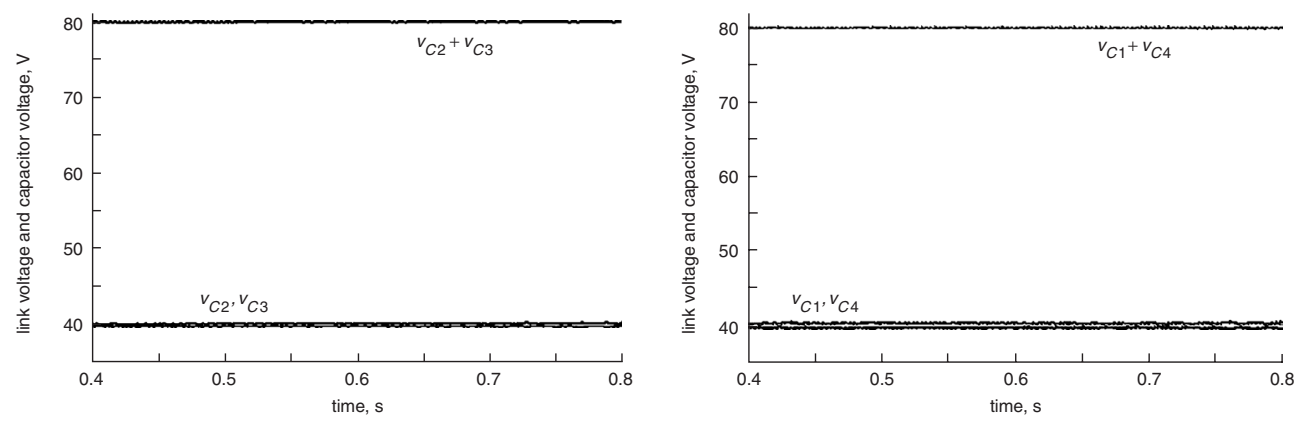

Fig. 3 Continued

causes an increase in $\Delta v_{C U}=\Delta_{C 4}-\Delta_{C 3}$ proportional to current $i_{A}$, an increase or decrease in $\Delta v_{C M}=v_{C 3}-v_{C 2}$ based on the resultant amplitude of ' $\left(-i_{A}-i_{C}\right)$ ', and a decrease in $\Delta v_{C L}=v_{C 2}-v_{C 1}$ proportional to $i_{C}$.

\subsection{Pairs of dual switching-state combinations}

It is evident from Fig. $2 c$ that the machine phase windings $A$ and $\mathrm{C}$ are connected across $\mathrm{C}_{3}$ and $\mathrm{C}_{2}$ respectively, when ' $10-1,000$ ' (for $\mathrm{A}^{\prime}{ }_{1}$ of $2 \mathrm{LV}$ group, Table-3) is switched. The same windings $A$ and $C$ are connected across $C_{2}$ and $C_{3}$ respectively, when ' $000,-101$ ' (for $\mathrm{A}^{\prime}{ }_{1}$ of $2 \mathrm{LV}$ group, Table 3, Fig. $2 c$ ) is switched. As described in the previous paragraph ' $10-1,000$ ' can be equivalently represented as ' $i_{A}$, $\left(-i_{A}-i_{C}\right), i_{C}$ ', similarly, based on Table 5 , it is found that ' $000,-101$ ' (Fig. $2 c$ ) can be equivalently represented as ' $-i_{C}$, $\left(i_{A}+i_{C}\right),-i_{A}$. These equivalent representations show that the switching-state combinations ' $10-1,000$ ' and ' $000,-101$ ' of $\mathrm{A}^{\prime}{ }_{1}$ (Fig. $2 c$ ) cause the equal and opposite currents ' $\left(-i_{A}-i_{C}\right)$ ' and ' $\left(i_{A}+i_{C}\right)$ ', respectively, through the middle DC-neutral (i.e. current $i_{2}$, Fig. 1f). Hence it is clear from (9) that these two switching-sate combinations produce exactly the opposite effect on the charge balancing of the inner two capacitors of the DC link i.e. on $\Delta v_{C M}=v_{C 3}-v_{C 2}$ (Fig. 1f). Therefore ' $10-1,000$ ' and ' $000,-101$ ' (Fig. 2c) are termed as a pair of middle DC-neutral dual switching-state combinations (MNDS) of $\mathrm{A}^{\prime}{ }_{1}$. Different possible MNDS pairs of voltage space vectors (Table 3 ) are listed in Table 6. For voltage vector $\mathrm{A}^{\prime}{ }_{1},{ }^{\prime} 02-2,-12-1$ ' makes one MNDS pair with ' $1-21,0-22$ ' and forms another MNDS pair with '112,01-1' also, shown with the help of a bidirectional arrow in Table 6.

Similarly, '10-1,000' and '20-2,10-1' (of $\mathrm{A}^{\prime}{ }_{1}$, Fig. 2c), with equivalent representations ' $i_{A},\left(-i_{A}-i_{C}\right), i_{C}$ ' and ' $-i_{A}$, 
Table 7: Chosen redundant switching-state combinations for $P$ S and $N$ S durations with respective equivalent representations and $2 T_{S}$ equivalent representation for different voltage space vectors in $30^{\circ}$ segment of voltage space phasor structure

Voltage Chosen switching-state combinations with respective equivalent representa-

space tions for open-loop control scheme (inverter A, inverter $A^{\prime}$ )

vector loca-

tion
$2 T_{S}$ equivalent representation for voltage vectors satisfying general balancing form $(x, z,-x)$

P_S duration N_S duration

\begin{tabular}{|c|c|c|c|}
\hline $\mathrm{O}^{\prime}$ & $000,000(z, z, z)$ & & $z, z, z$ \\
\hline $\mathrm{A}^{\prime}{ }_{1}$ & $10-1,000\left(i_{A},\left(-i_{A}-i_{C}\right), i_{C}\right)$ & $000,-101\left(-i_{C}\left(i_{A}+i_{C}\right),-i_{A}\right)$ & $\left(i_{A}-i_{C}\right), z_{1}\left(i_{C}-i_{A}\right)$ \\
\hline $\mathrm{B}^{\prime}{ }_{1}$ & $10-1,-101\left(\left(i_{A}-i_{C}\right), z_{,}\left(-i_{A}+i_{C}\right)\right)$ & & $\left(i_{A}-i_{C}\right), z_{1}\left(-i_{A}+i_{C}\right)$ \\
\hline $\mathrm{B}_{2}^{\prime}$ & $01-1,-101\left(\left(i_{B}-i_{C}\right),\left(i_{A}-i_{B}\right),\left(-i_{A}+i_{C}\right)\right)$ & $10-1,0-11\left(\left(i_{A}-i_{C}\right),\left(-i_{A}+i_{B}\right),\left(-i_{B}+i_{C}\right)\right)$ & $\left(i_{A}+i_{B}-2 i_{C}\right), z,\left(-i_{A}-i_{B}+2 i_{C}\right)$ \\
\hline $\mathrm{C}^{\prime}{ }_{1}$ & $20-2,-101\left(-i_{C}, z_{,}-i_{A}\right)$ & $10-1,-202\left(i_{A}, z, i_{C}\right)$ & $\left(-i_{C}+i_{A}\right), z,\left(-i_{A}+i_{C}\right)$ \\
\hline $\mathrm{C}_{2}^{\prime}$ & $2-1-1,0-22\left(z,-i_{A},\left(i_{B}+i_{C}\right)\right)$ & $02-2,-211\left(\left(-i_{B}-i_{C}\right), i_{A}, z\right)$ & $\left(-i_{B}-i_{C}\right), z,\left(i_{B}+i_{C}\right)$ \\
\hline $\mathrm{D}^{\prime}{ }_{1}$ & $20-2,-202(z, z, z)$ & & $z, z, z$ \\
\hline $\mathrm{D}_{2}^{\prime}$ & $11-2,-202\left(\left(i_{A}+i_{B}\right),-i_{B}, z\right)$ & $20-2,-1-12\left(z, i_{B},\left(-i_{A}-i_{B}\right)\right)$ & $\left(i_{A}+i_{B}\right), z,\left(-i_{A}-i_{B}\right)$ \\
\hline $\mathrm{D}_{3}^{\prime}$ & $11-2,-1-12\left(\left(i_{A}+i_{B}\right), z_{1}\left(-i_{A}-i_{B}\right)\right)$ & & $\left(i_{A}+i_{B}\right), z,\left(-i_{A}-i_{B}\right)$ \\
\hline
\end{tabular}

$z,-i_{C}$, respectively, (Table 5) produce exactly opposite effects on the voltage balancing of the upper two capacitors of the DC link (i.e. on $\Delta v_{C U}=v_{C 4}-v_{C 3}$, Fig. 1f) as well as on the voltage balancing of the lower two capacitors of the DC link (i.e. on $\Delta v_{C L}=v_{C 2}-v_{C 1}$, Fig. 1f). Therefore ' $10-1,000$ ' and '20-2,10-1' form an example of upper and lower DC-neutral dual switching-state combinations (ULNDS) pair (Table 6). Each switching-state combination that forms the ULNDS pair with some switching-state combination, and also forms the MNDS pair with some other switching-state combination of the same voltage vector, is marked shaded in Table 6. For example, ' 10 1,000 ' forms the MNDS pair with ' $000,-101$ ' and the ULNDS pair with ' $20-2,10-1$ ' (Fig. 2c), therefore ' 10 1,000 ' is shown shaded in the column of ULNDS pairs of Table 6.

\section{Possibility of capacitor-voltage balancing with single DC power supply}

Consider the reference voltage space vector in a sector formed by the space vectors $\mathrm{A}^{\prime}{ }_{1}, \mathrm{~B}^{\prime}{ }_{1}$ and $\mathrm{B}_{2}^{\prime}$ of Fig. $1 c$ for the three-level operation of the drive. Figure $2 d$ shows the selection of switching state combinations for $\mathrm{A}^{\prime}{ }_{1}, \mathrm{~B}^{\prime}{ }_{1}$ and $\mathrm{B}_{2}^{\prime}$ during successive sampling intervals, where $T_{S}$ indicates one sampling interval of the PWM controller. It is seen from Fig. $2 d$ that when it is required to switch $\mathrm{A}^{\prime}{ }_{1}$ by switching ULNDS pairs of ' $10-1,000$ ', '20-2,10-1', and '000-101', '-101,-202' (Table 6), the net current for each of the three DC-neutrals (Fig. 1f) can be made zero in every four sampling intervals. Similarly, it can be shown that, only by proper selection of MNDS and ULNDS pairs of any voltage vector of the $2 \mathrm{LV}$ and $3 \mathrm{LV}$ groups (Table 6), the net current through all the three DC-neutrals can be made to zero within two or a maximum of four sampling intervals (Fig. 2d). Hence for two-level and three-level operation of drive the capacitor-voltage balancing can be achieved for the inverter-fed drive of Fig. $1 e$ without any additional hardware. In practice, for position of reference voltage space vector in any given sector, based on the volt-second balance, the space vector PWM algorithm switches each of the three voltage vectors forming that sector for a definite time in each sampling interval. Figure $2 e$ shows a typical sequence pattern of the proposed switching-state combinations (Fig. $2 d$ ), where SEQ is a digital signal synchronised with the PWM sampling duration $T_{S}$ and it has a period equal to $2 * T_{S}$ and a duty ratio equal to $50 \%$. In Fig. $2 e$, P_S means the positive sequence duration (SEQ is high) whereas N_S means the negative sequence duration (SEQ is low).

It is evident from Table 6 that the possibility of getting MNDS and especially the ULNDS pairs for each voltage vector reduces inherently as one moves from the centre (ZV group, Table 4) to successive outer hexagons (up to the $5 \mathrm{LV}$ group, Table 4) of Fig. 1c. Unlike the voltage vectors of the $2 \mathrm{LV}$ and 3LV groups (Table 6), for most of the voltage vectors of the 4LV and 5LV groups (Table 6), the sequential switching of redundant switching-state combinations of any voltage vector alone does not provide zero net current through all the DC-neutrals (Fig. 1f). Efforts are also made to explore the possibility of getting the zero net currents flowing through DC-neutrals by selecting the proper switching-state combinations of the three adjacent voltage vectors forming a triangular sector, which can altogether provide the compensating effects. As an example, Fig. $2 f$ shows a selected sequence of switching-state combinations for two consecutive sampling intervals, when the reference voltage vector is considered in a sector formed by $\mathrm{B}_{1}^{\prime}, \mathrm{B}_{2}^{\prime}$ and $\mathrm{C}_{2}^{\prime}$ of Fig. $1 c$ (four-level operation). For this sequence (Fig. 2f), based on Table 6, the net value of DC-neutral currents after the two sampling intervals, results into ' $x, z$, $-x$, where $x=\left(-i_{A}+2_{i B}+i_{C}\right)$ and may be a nonzero value. This makes the problem of DC-link capacitor-voltage balancing (in association with common-mode voltage elimination) unsolvable for four-level and five-level operation unless extra hardware control is added in the drive system of Fig. 1e for the control of upper and lower DCneutral currents. Similar inherent limitations at the higher modulation range have been pointed out in the literature $[6-8,11]$ for achieving the DC-link capacitor-voltage balancing alone in conventional multilevel inverters. The addition of extra control hardware (consisting of active and passive components and control circuitry) in the form of buck-boost converter (DC choppers) [7, 8] or controlled front-end converter [9] is suggested in the literature for capacitor-voltage balancing in NPC five-level inverters. 


\section{Proposed scheme for DC-link capacitor-voltage balancing}

As shown in Fig. $3 a$ it is proposed to introduce a power supply of $V_{d c} / 4$ for supplying the inner two capacitors $\left(C_{3}\right.$ and $\left.C_{2}\right)$ in association with the DC power supply of $V_{d c} / 2$ which supplies all the four capacitors of the DC-link.
Now, for the same redundant switching states of Fig. $2 f$ (four-level operation), the $2 T_{S}$ equivalent circuit for the proposed modified inverter (Fig. 3a) is shown in Fig. $3 b$. Figure $3 b$ indicates that in a $2 T_{S}$ period the net current flow from the middle DC-neutral (i.e. $i_{2}$ ) becomes zero as expressed in (10). Therefore from (9) and (10) it can be shown that the voltage difference between the two middle
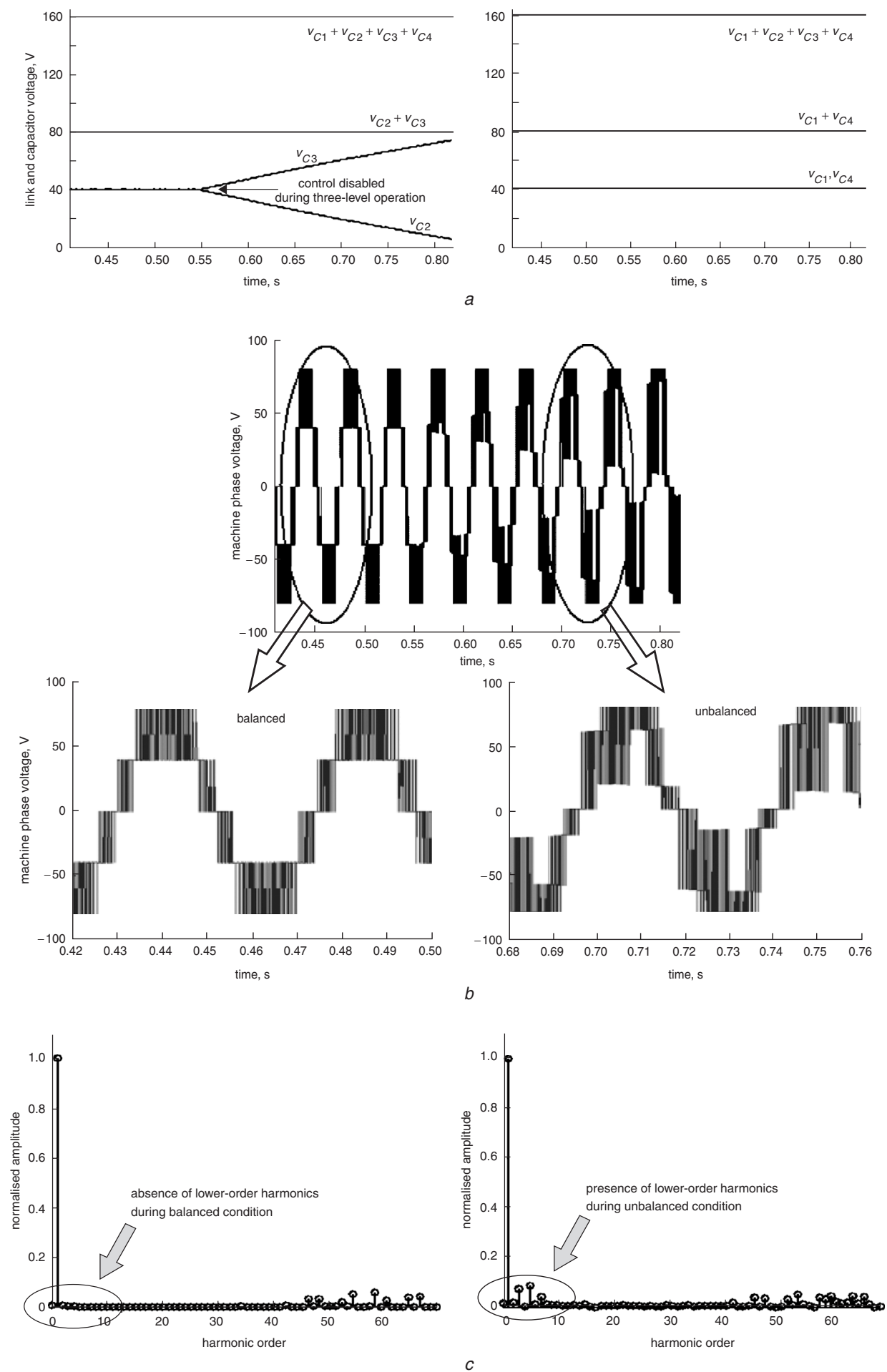

Fig. 4

$a$ Control is disabled during three-level operation: voltages of DC-link capacitors

$b$ Machine phase voltage $V_{A A^{\prime}}$ for operation of Fig. $4 a$

$c$ Normalised harmonic spectrums of $V_{A A^{\prime}}$ of Fig. $4 b$ during balanced and unbalanced conditions of capacitor voltages

$d$ Machine phase current $i_{A}$ for operation of Fig. $4 a$

$e$ Common-mode voltage $V_{C M}$ for operation of Fig. $4 a$

$f$ Control is disabled during five-level operation: voltages of DC-link capacitors

$g$ Machine phase voltage $V_{A A^{\prime}}$ for operation of Fig. $4 f$ 

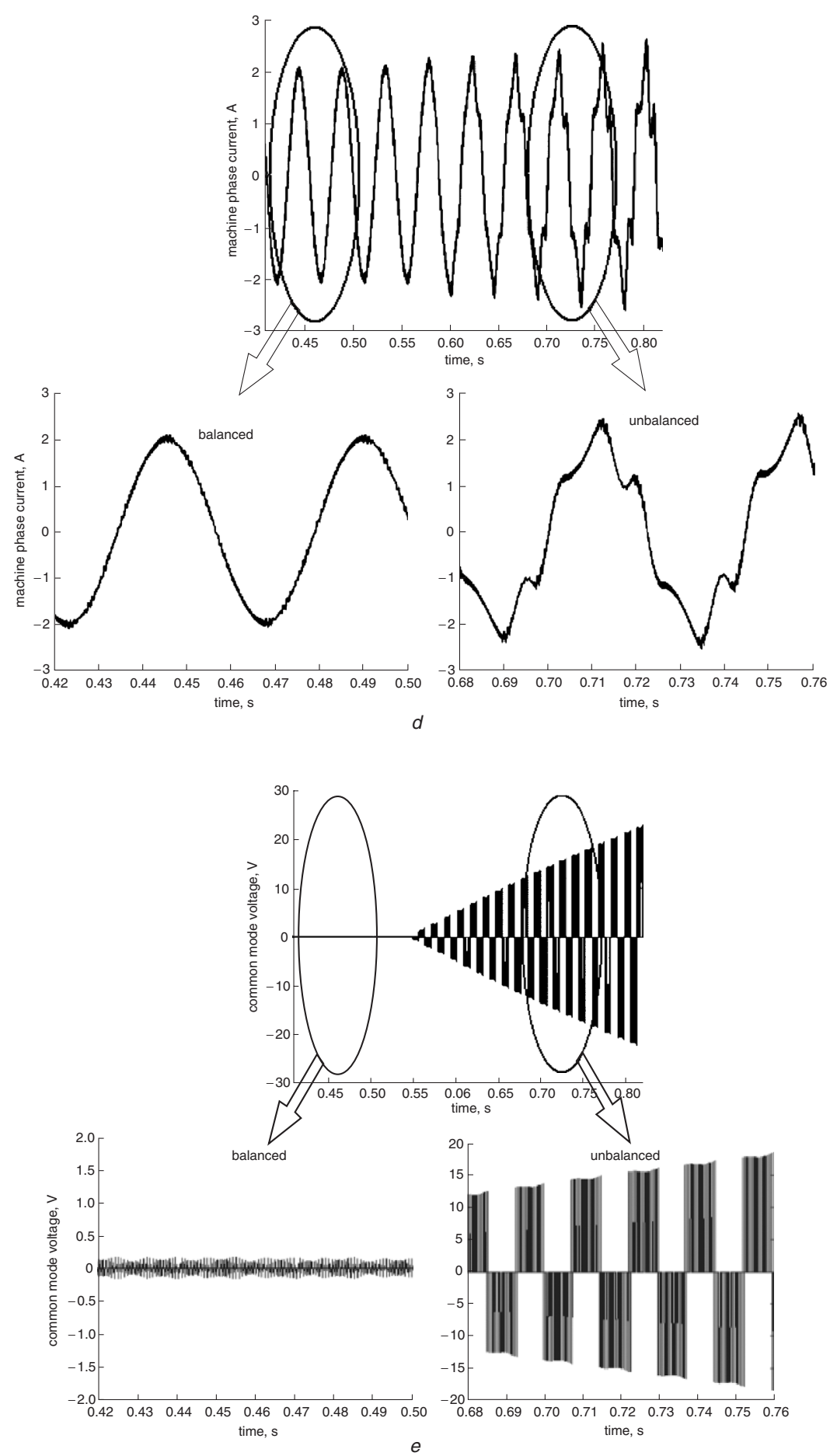

Fig. 4 Continued

capacitors of the DC-link becomes zero within 2Ts period, as indicated in (11). Based on (11), and considering that the additional DC power supply of $V_{d c} / 4$ (Fig. $3 a$ ) is of constant amplitude, it can be found that the middle two capacitors of the DC-link share equal voltage, as indicated in (12). From (9) and (12), the sum of the two voltage differences $\Delta v_{C U}$ and $\Delta v_{C L}$ can be given as (13). But equal and opposite values of DC-neutral currents $i_{3}$ and $i_{1}$ ( $x$ and $-x$ respectively, Fig. $3 b$ ) makes the sum of two voltage differences $\Delta v_{C U}$ and $\Delta v_{C L}$ (13) equal to zero, as shown in (14). Hence from (12) and (14) it is clear that the upper and lower capacitors of the DC-link also share equal amounts of total voltage $V_{d c} / 4\left(V_{d c} / 2-V_{d c} / 4\right.$, where $V_{d c} / 2$ is total DClink voltage and $V_{d c} / 4$ is the voltage shared equally by the middle two capacitors, Fig. 3a), as indicated by (15). It can be concluded from (12) and (15) that all the four capacitors of the DC-link (Fig. $3 a$ ) are at equal potentials resulting into the balancing of capacitor voltages as shown in (16).

in the $2 T_{s}$ period, $i_{2} \rightarrow 0$

$$
\begin{gathered}
\therefore \Delta v_{C M}=v_{C 3}-v_{C 2}=\frac{1}{C} \int i_{2} d t=0 \\
\therefore v_{C 3}=v_{C 2}=V_{d c} / 8
\end{gathered}
$$

$$
\Delta v_{C U}+\Delta v_{C L}=v_{C 4}-v_{C 1}=\frac{1}{C} \int\left(i_{3}+i_{1}\right) d t
$$



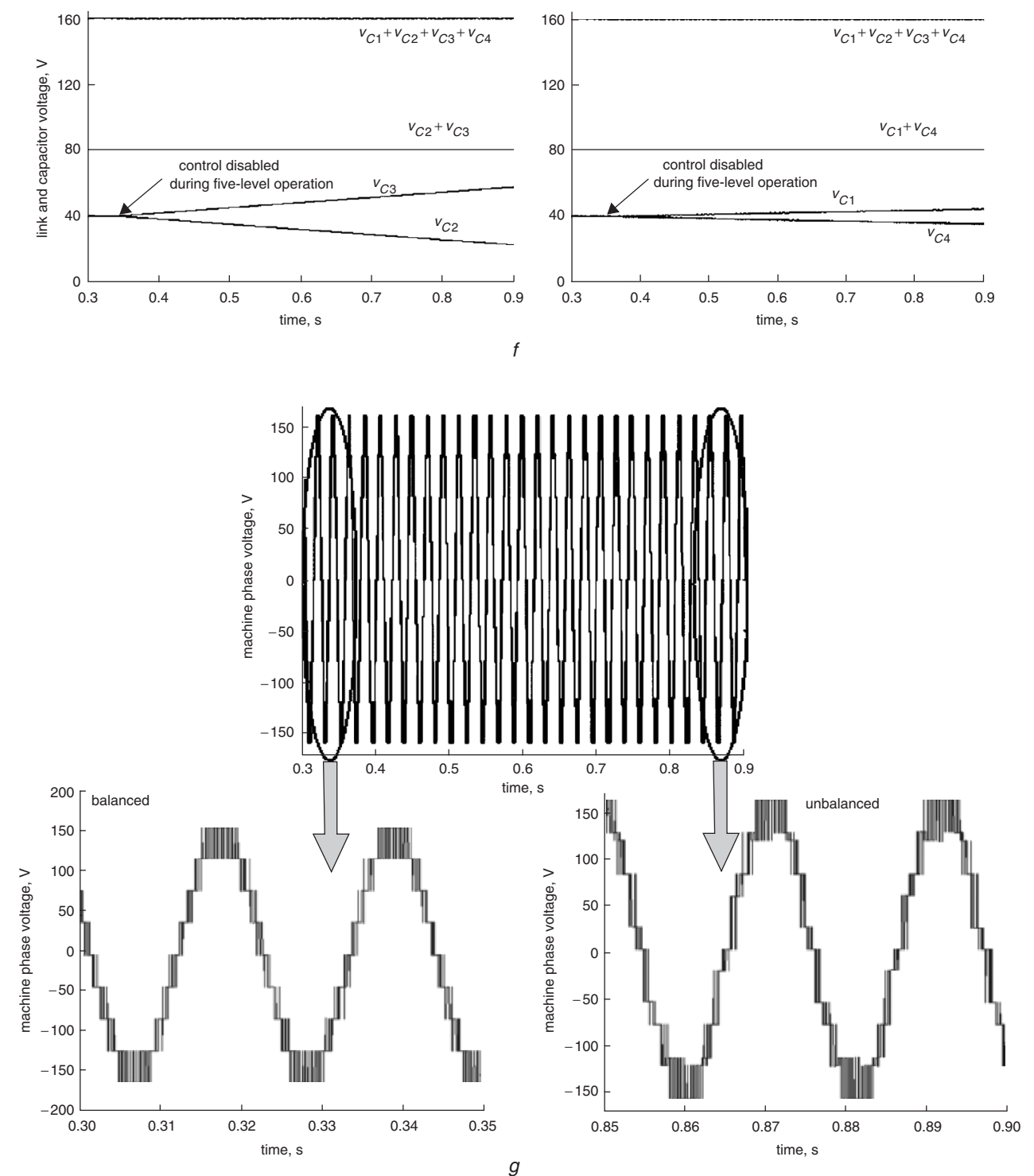

Fig. 4 Continued

$$
\begin{gathered}
\Delta v_{C U}+\Delta v_{C L}=v_{C 4}-v_{C 1}=\frac{1}{C} \int(x-x) d t=0 \\
v_{C 4}=v_{C 1}=V_{d c} / 8 \\
\therefore v_{C 4}=v_{C 3}=v_{C 2}=v_{C 1}=V_{d c} / 8
\end{gathered}
$$

Hence, with the modified proposed power schematic of Fig. $3 a$, the conditions for achieving the balancing of the DC-link capacitor voltages is not restricted to ' $z, z, z$ '. But the condition ' $x, z,-x$ ' also provides the balancing of the DC-link capacitors, where $x$ can be zero or any nonzero value. Table 7 shows the chosen redundant switching-state combinations for P S and N S (Section 5) durations with respective equivalent representations for a $30^{\circ}$ segment $\left(\mathrm{D}_{1}^{\prime} \mathrm{O}^{\prime} \mathrm{D}_{3}^{\prime}\right)$ of Fig. $1 c$. The switching states of Table 7 are chosen in such a way that the average voltage unbalance caused in one sampling interval (by $\mathrm{P}$ S switching states) is nullified in the next sampling interval (by N_S switching states). It can be easily verified from $2 T_{s}$ equivalent representation in the last column of Table 7 that in a maximum of two sampling intervals the alternate switching of selected redundant switching-state combinations for each voltage vector provides the DC-neutral currents ' $x, z,-x$ ' (where $x$ is zero or any nonzero value). Hence, the

capacitor-voltage balancing can be achieved by PWM control for the tip of the reference voltage vector in any of the sectors of Fig. 1c. The proper switching-state combinations for all other voltage vectors of Fig. $1 c$ are also found in a similar way.

Figure $3 c$ shows a block diagram of the $V / f$ control scheme used for the proposed drive (Fig. $3 a$ ). Figures $3 d-3 f$ show the simulation results of starting transients when the machine is started with a command speed of five-level operation under $V / f$ control. The machine phase voltage waveform Fig. $3 d$ shows the smooth transition from threeto four-level and four- to five-level modes of operation. The elimination of common-mode voltage (5) for different operating levels of the drive is clearly seen in Fig. $3 e$. The individual capacitor voltages (Fig. 3f) show the balancing of capacitor voltages to a fairly good extent. Similarly, Figs. $3 g-3 i$ show the simulation results of transition from five-level to overmodulation operation. It is evident from different waveforms of Figs. $3 d-3 i$ that the proposed scheme is capable of eliminating the common-mode voltage and capacitor-voltage unbalance, throughout the operating range of drive including the overmodulation.

The effectiveness of the proposed scheme is demonstrated by disabling the controller (by clamping the SEQ signal 


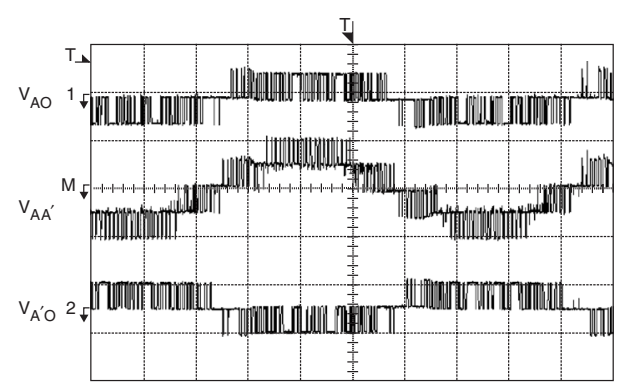

a
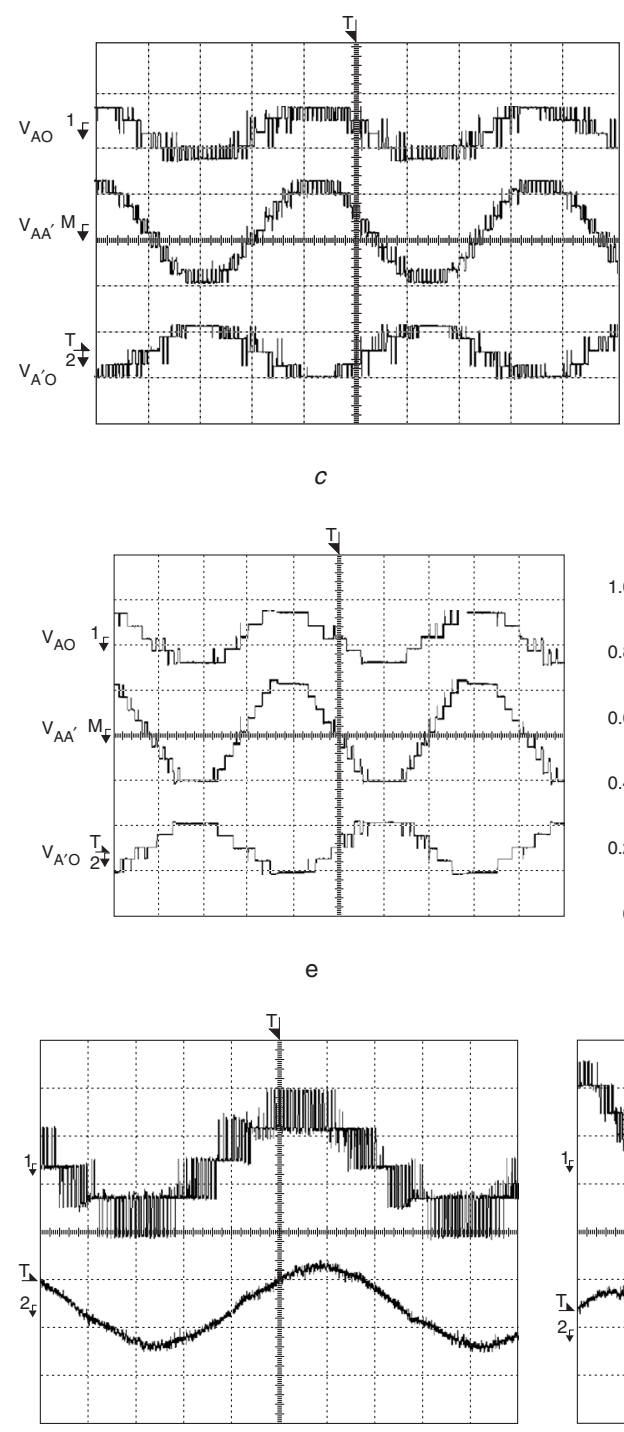

$g$
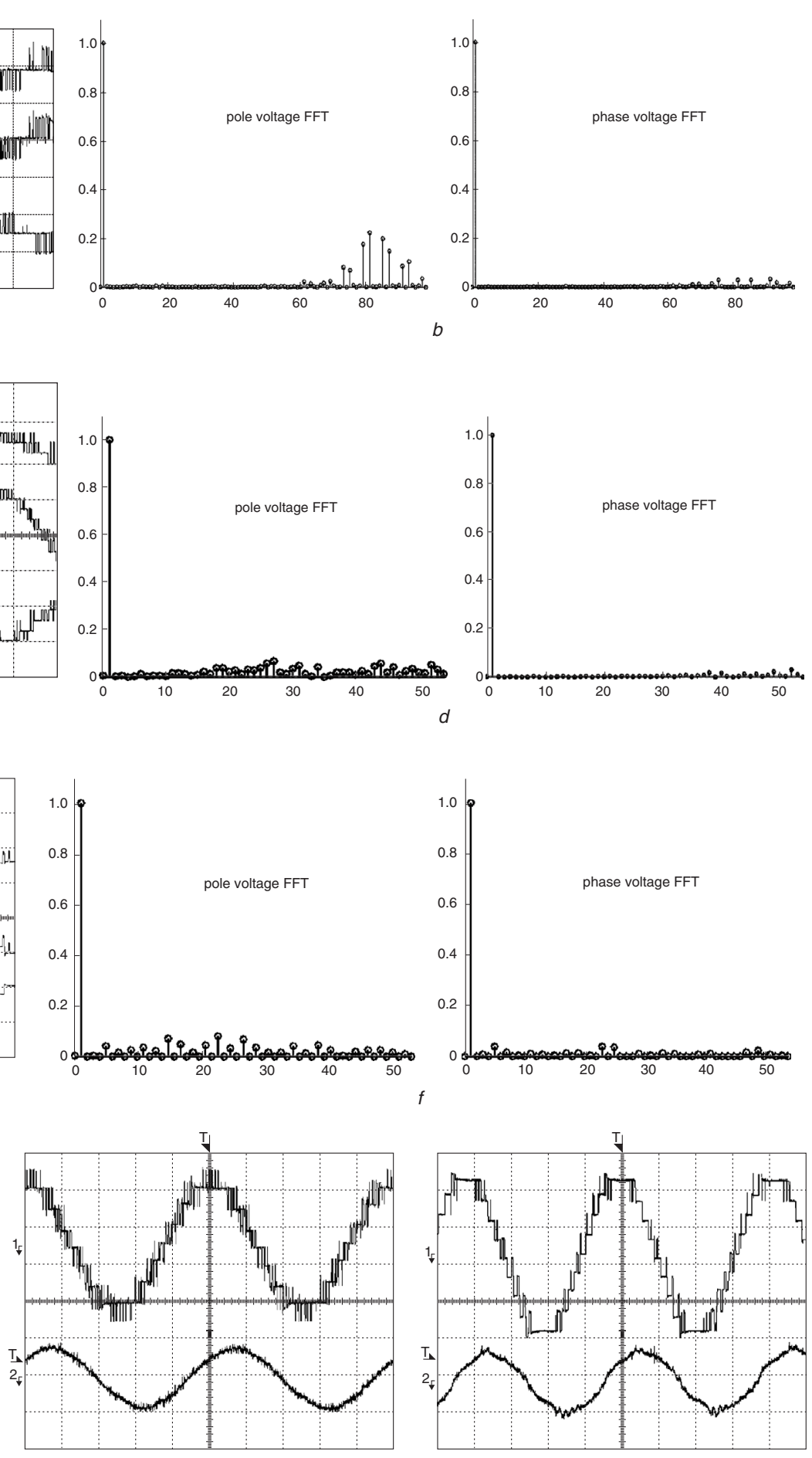

$h$

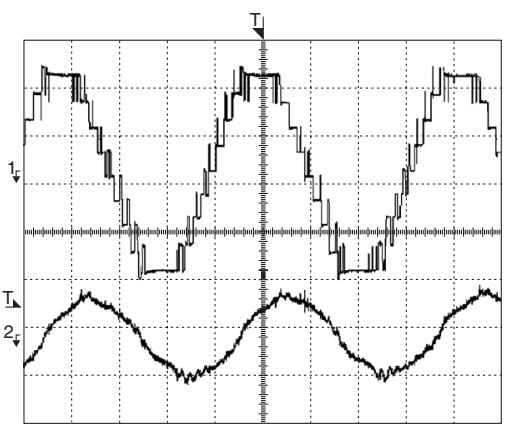

Fig. 5

$a$ Pole voltage $\mathrm{V}_{\mathrm{AO}}$ and $\mathrm{V}_{\mathrm{A}^{\prime} \mathrm{O}}$ and machine phase voltage $\mathrm{V}_{\mathrm{AA}^{\prime}}$ for three-level operation $y$-axis: 1 div. $=50 \mathrm{~V}, x$-axis: 1 div. $=10 \mathrm{~ms}$

$b$ Normalised harmonic spectrum of pole voltage and phase voltage of Fig. $5 a$ $x$-axis: order of harmonic, $y$-axis: normalised amplitude

$c$ Pole voltage $\mathrm{V}_{\mathrm{AO}}$ and $\mathrm{V}_{\mathrm{A}^{\prime} \mathrm{O}}$ and machine phase voltage $\mathrm{V}_{\mathrm{AA}}$ for five-level operation $y$-axis: 1 div. $=100 \mathrm{~V}, x$-axis: 1 div. $=5 \mathrm{~ms}$

$d$ Normalised harmonic spectrum of pole voltage and phase voltage of Fig. $5 c$ $x$-axis: order of harmonic, $y$-axis: normalised amplitude

$e$ Pole voltage $\mathrm{V}_{\mathrm{AO}}$ and $\mathrm{V}_{\mathrm{A}^{\prime} \mathrm{O}}$ and machine phase voltage $\mathrm{V}_{\mathrm{AA}^{\prime}}$ for 24-step operation $y$-axis: 1 div. $=100 \mathrm{~V}, x$-axis: 1 div. $=5 \mathrm{~ms}$

$f$ the Normalised harmonic spectrum of pole voltage and phase voltage of Fig. $5 e$ $x$-axis: order of harmonic, $y$-axis: normalised amplitude $g$ Machine phase voltage $V_{A A^{\prime}}$ and machine phase current $i_{A}$ for three-level operation $y$-axis: upper trace: 1 div. $=33 \mathrm{~V}$, lower trace: 1 div. $=2 \mathrm{~A}, x$-axis: 1 div. $=10 \mathrm{~ms}$ $h$ Machine phase voltage $\mathrm{V}_{\mathrm{AA}^{\prime}}$ and machine phase current $i_{A}$ for five-level operation $y$-axis; upper trace: 1 div. $=50 \mathrm{~V}$, lower trace: 1 div. $=2 \mathrm{~A}, x$-axis: 1 div. $=5 \mathrm{~ms}$

$i$ Machine phase voltage $V_{A A^{\prime}}$ and machine phase current $i_{A}$ for over-modulation operation $y$-axis; upper trace: 1 div. $=50 \mathrm{~V}$, lower trace: 1 div. $=2 \mathrm{~A}, x$-axis: 1 div. $=5 \mathrm{~ms}$ 
Fig. $3 c$ to either high or low level) in three-level operation as shown in Figs. $4 a-4 e$. Once the controller is disabled the gradual divergence in the voltages of middle two capacitors $v_{C 3}$ and $v_{C 2}$ is clearly observed (Fig. $4 a$ ). This leads to distorted machine phase voltage (Figs. $4 b$ and $4 c$ ), distorted phase current (Fig. 4d) and increased common-mode voltage (Fig. 4e). Similar results are obtained, as shown in Figs. $4 f$ and $4 g$, when the control scheme is disabled in fivelevel mode of operation. Now, both the pairs of capacitors i.e. the pair of inner capacitors $C_{2}$ and $C_{3}$ and the pair of outer capacitors $C_{1}$ and $C_{4}$ of the DC-link of Fig. $3 a$ exhibit the voltage imbalance (Fig. $4 f$ ).
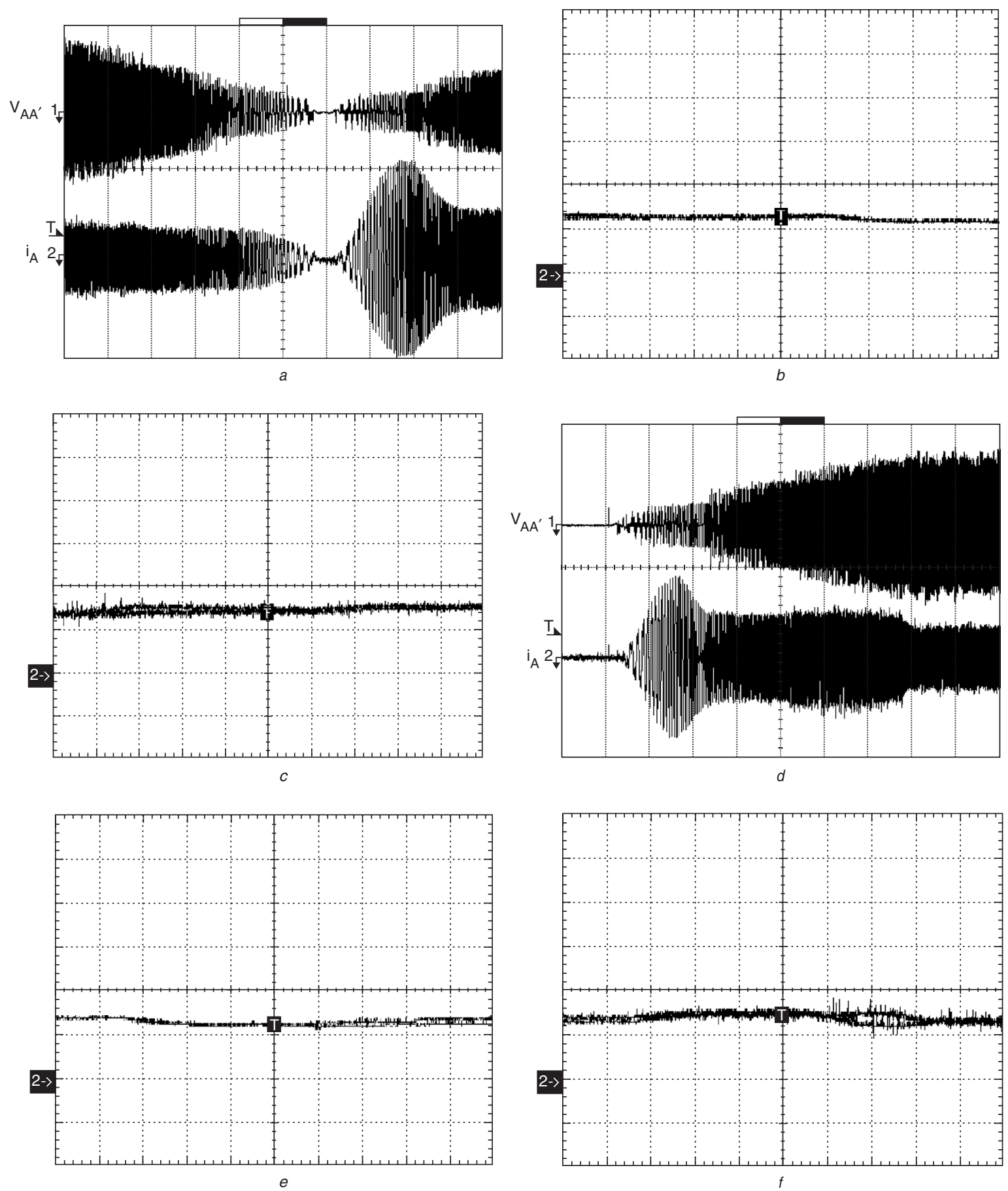

Fig. 6

a Speed reversal in five-level operating mode: machine phase voltage $V_{A A^{\prime}}$ and machine phase current $i_{A}$

$y$-axis; upper trace: 1 div. $=50 \mathrm{~V}$, lower trace: 1 div. $=2 \mathrm{~A}, x$-axis: 1 div. $=2 \mathrm{~s}$

$b$ Capacitor voltages $v_{C 2}$ and $v_{C 3}$ for operation of Fig. $6 a$

$y$-axis: 1 div. $=20 \mathrm{~V}, x$-axis: 1 div. $=2 \mathrm{~s}$

$c$ Capacitor voltages $v_{C 1}$ and $v_{C 4}$ for operation of Fig. $6 a$

$y$-axis: 1 div. $=20 \mathrm{~V}, x$-axis: 1 div. $=2 \mathrm{~s}$

$d$ Starting of machine by giving five-level operation speed command: machine phase voltage $V_{A A^{\prime}}$ and machine phase current $i_{A}$

$y$-axis; upper trace: 1 div. $=50 \mathrm{~V}$, lower trace: 1 div. $=2 \mathrm{~A}, x$-axis: 1 div. $=2 \mathrm{~s}$

$e$ Capacitor voltages $v_{C 2}$ and $v_{C 3}$ for operation of Fig. $6 d$

$y$-axis: 1 div. $=20 \mathrm{~V}, x$-axis: 1 div. $=2 \mathrm{~s}$

$f$ Capacitor voltages $v_{C 1}$ and $v_{C 4}$ for operation of Fig. $6 d$

$y$-axis: 1 div. $=20 \mathrm{~V}, x$-axis: 1 div. $=2 \mathrm{~s}$ 


\section{Experimental results}

The proposed five-level inverter scheme (Fig. $3 a$ ) is tested on a laboratory prototype of a $1.5 \mathrm{~kW}$ open-end-winding induction motor drive with $V / f$ control (Fig. 3c) for different modulation indices covering the entire speed range. The DSP tool TI TMX320F240PQ and the CPLD Xilinx XC95108-20PC84C are used for implementing the proposed control scheme of Fig. 3c. The DC-link voltage of around $120 \mathrm{~V}$ is used for the inverter and thus the individual DC-link capacitor voltages are around $30 \mathrm{~V}$. In the proposed PWM scheme the deadbands of the inverter legs are properly tuned to avoid any common-mode voltage generated due to deadband mismatch. The carrier frequency used for PWM generation is limited to $1.2 \mathrm{kHz}$.

The performance of the drive is verified in steady-state and transient operating conditions by varying the operating speed of the drive in the linear as well as overmodulation range. The pole and phase voltage waveforms and their normalised harmonic spectra (FFTs) for inverter operation in different operating levels are presented in Figs. 5a-5f. Figure $5 a$ (three-level operation) shows that the pole voltages $V_{A O}$ and $V_{A^{\prime} O}$ of the two inverters (A and $\mathrm{A}^{\prime}$ of Fig. 3a) are symmetric and out of phase with each other, as expected. The FFTs of the pole voltage and phase voltage (Fig. $5 b$ ) show the absence of triplen harmonic components, confirming the elimination of common-mode voltage. The contents of any even harmonics in the pole voltages cancel each other in the phase voltage (Fig. 5b) and the fundamental component of pole voltages add in the phase voltages. Similar results of pole voltages and phase voltage waveforms, confirm the absence of triplen harmonics for five-level operation of the proposed drive, as shown in Figs. $5 c$ and $5 d$. The 24-step operation (overmodulation) is characterised by the 23rd and 25th harmonic frequency components in the pole as well as phase voltage FFTs (Fig. 5f). From the experimental results shown in Figs. $5 a-5 f$, it is clear that the proposed scheme eliminates the common-mode voltage at individual inverter poles as well as at machine phase windings throughout the operating range of the drive.

Figures $5 g$ and $5 h$ show the steady-state waveforms of the machine phase voltage and current for the three-level and five-level operation of the drive, respectively, whereas Fig. $5 i$ shows the machine phase voltage and current for the overmodulation range.

Figures $6 a-6 f$ show the transient performance of the proposed drive. In Fig. $6 a$ the waveforms of the machine phase voltage (upper trace) and the machine phase current (lower trace) show the smooth transitions of operating levels of the inverter during speed reversal. Figure $6 b$ shows that the middle two capacitors $\left(C_{2}\right.$ and $C_{3}$, Fig. $\left.3 a\right)$ of the DC-link share the equal voltage, while equal sharing of voltage between the upper and lower capacitors $\left(C_{1}\right.$ and $C_{4}$, Fig. $3 a$ ) of the DC-link is evident from the Fig. $6 c$. It is also clear from Figs. $6 b$ and $6 c$ that all the four capacitors of the DC-link share equal voltage throughout the operating range of the drive. Similar results, demonstrating capacitorvoltage balancing, are obtained during the starting operation of the drive as shown in Figs. $6 d-6 f$. The experimental results presented (Figs. 5a-6f) demonstrate the ability of controller to simultaneously eliminate the common-mode voltage and imbalance in DC-link capacitor voltages in the steady state as well as during transient operation in the entire operating range of the drive.

\section{Conclusions}

A five-level inverter scheme for induction motor drive has been proposed to achieve the simultaneous elimination of common-mode voltage and DC-link capacitor-voltage imbalance. The operating limitations of achieving this dual task for the five-level inverter configuration with a single DC power supply are investigated. A switching strategy for the five-level inverter topology with two DC power supplies is proposed to achieve the dual task throughout the operating range of the drive. The proposed drive offers a simple power-bus structure with increased redundant switching states for inverter voltage vectors, and requires a lower voltage blocking capacity of power devices as compared with a conventional single five-level inverter-fed drive. As only the availability of redundant switching states for the inverter voltage vectors is exploited, the dual task is achieved without disturbing the fundamental component of the inverter output voltage and the scheme does not need any extra control circuit hardware. The performance of proposed scheme is demonstrated by the results of simulation studies, and experimentally verified on a $1.5 \mathrm{~kW}$ open-end-winding induction motor drive in the linear as well as overmodulation range.

\section{References}

1 Zhang, H., Von Jouanne, A., Dai, S., Wallace, A.K., and Wang, F.: 'Multilevel inverter modulation schemes to eliminate common-mode voltages', IEEE Trans. Ind. Appl., 2000, 36, (6), pp. 1645-1653

2 Kim, H.J., Lee, H.D., and Sul, S.: 'A new PWM strategy for common-mode voltage reduction in neutral-point-clamped inverterfed AC motor drives', IEEE Trans. Ind. Appl., 2001, 37, (6), pp. $1840-1845$

3 Loh, P.C., Holmes, D.G., Fukuta, Y., and Lipo, T.A.: 'Reduced common-mode modulation strategies for cascaded multilevel inverters', IEEE Trans. Ind. Appl., 2003, 39, (5), pp. 1386-1395

4 Kanchan, R.S., Tekwani, P.N., Baiju, M.R., Gopakumar, K., and Pittet, A.: 'Three-level inverter configuration with common-mode elimination for induction motor drive', IEE Proc. EPA, 2005, 152, (2), pp. $261-270$

5 Tekwani, P.N., Kanchan, R.S., Gopakumar, K., and Vezzini, A.: 'A five-level inverter topology, with common-mode voltage elimination for induction motor drives'. Accepted for 11th EPE Conf., Dresden, Germany, 11-14 September 2005

6 Newton, C., and Sumner, M.: 'Neutral-point control for multilevel inverters: theory, design and operational limitations'. Proc. of IEEE IAS Conf., New Orleans, 5-9 Oct. 1997, pp. 1336-1343

7 Newton, C., and Summer, M.: 'Novel technique for maintaining balanced internal DC-link voltages in diode-clamped five-level inverters', IEE Proc. EPA, 1999, 146, (3), pp. 341-349

8 Choi, N.S., Cho, J.G., and Cho, G.H.: 'A general circuit topology of multilevel inverter'. Proc. of 22nd Annual IEEE Conf., PESC`91, 24-27 June 1991, pp. 96-103

9 Marchesoni, M., and Tenca, P.: 'Diode-clamped multilevel converters: a practicable way to balance DC-link voltages', IEEE Trans. Ind. Electron., 2002, 49, (4), pp. 752-765

10 Peng, F.Z.: 'A generalized multilevel inverter topology with self voltage balancing', IEEE Trans. Ind. Appl., 2001, 37, (2), pp. 611-618

11 Pou, J., Pindado, R., and Boroyevich, D.: 'Voltage-balance limits in four-level diode-clamped converters with passive front ends', IEEE Trans. Ind. Electron., 2005, 52, (1), pp. 190-196

12 Jouanne, A.V., Dai, S., and Zhang, H.: 'A multilevel inverter approach providing DC-link balancing, ride-through enhancement, and common-mode voltage elimination', IEEE Trans. Ind. Electron., 2002, 49, (4), pp. 739-745

13 Kanchan, R.S., Tekwani, P.N., and Gopakumar, K.: 'Three-level inverter scheme with common-mode voltage elimination and DC-link capacitor-voltage balancing for an open-end-winding induction motor drive'. Proc. of IEEE Int. Conf. on. Electric Machines and Drives, IEMDC-2005, San Antonio, USA, 15-18 May 2005, pp. 1445-1452

14 Baiju, M.R., Mohapatra, K.K., Kanchan, R.S., and Gopakumar, K.: 'A dual two-level inverter scheme with common mode voltage elimination for an induction motor drive', IEEE Trans. Power Electron., 2004, 19, (3), pp. 794-805 